\title{
Neural differentiation footprints of mesenchymal stem cell by fetal brain extract
}

\section{Iman Razeghian-Jahromi ( $\square$ razejahromi@yahoo.com )}

Shiraz University of Medical Sciences https://orcid.org/0000-0001-8137-786X

\section{Davood Mehrabani}

Shiraz University of Medical Sciences

\section{Ali Mohammadi}

Shiraz University

\section{Mohammad Mehdi Ghahremani Seno}

Ferdowsi University of Mashhad

\section{Shahrokh Zare}

Shiraz University of Medical Sciences

Mohammad Javad Zibaeenezhad

Shiraz University of Medical Sciences

\section{Ashkan Mowla}

California Southern University

\section{Research}

Keywords: mesenchymal stem cells, neural differentiation, fetal brain extract

Posted Date: May 7th, 2020

DOI: https://doi.org/10.21203/rs.3.rs-25979/v1

License: (c) (1) This work is licensed under a Creative Commons Attribution 4.0 International License.

Read Full License 


\section{Neural differentiation footprints of mesenchymal stem cell by fetal brain}

\section{extract}

Iman Razeghian-Jahromi ${ }^{1 *}$; Davood Mehrabani²; Ali Mohammadi ${ }^{3}$; Mohammad Mehdi Ghahremani Seno $^{4 *}$; Shahrokh Zare ${ }^{3}$; Mohammad Javad Zibaeenezhad ${ }^{1}$; Ashkan Mowla ${ }^{5}$

${ }^{1}$ Cardiovascular Research Center, Shiraz University of Medical Sciences, Shiraz, Iran

${ }^{2}$ Stem cell Technology Research Center, Shiraz University of Medical Sciences, Shiraz, Iran

${ }^{3}$ Division of Biotechnology, Department of Pathobiology, School of Veterinary Medicine, Shiraz University, Shiraz, Iran

${ }^{4}$ Division of Biotechnology, Department of Pathobiology, School of Veterinary Medicine, Ferdowsi University, Mashhad, Iran

${ }^{5}$ Department of Neurosurgical Surgery, Keck School of Medicine, University of Southern California, CA, USA

*Co-authorship: Mehdi Ghahremani Seno

*Corresponding author: Iman Razeghian-Jahromi

Postal address: Cardiovascular Research Center, $3^{\text {rd }}$ floor, Mohammad rasoolallah research tower, Namazi Hospital, Shiraz, Iran.

Postal code: 71936-35899 
Tel: +989173057849

Fax: +98 7136122235

razejahromi@yahoo.com

\section{Abstract}

Background

Stem cells has brought promising hope to improve impairment in different organs especially those with limited intrinsic regeneration capacity like nervous system. With the use of mesenchymal stem cells' (MSC) capacity to differentiate toward neural cells, this study aimed to examine the potential of fetal rat brain extract (FBE) as a biological inducer to mimic natural differentiation environment.

Methods

Bone marrow-MSCs were derived from Rattus norvegicus. After characterization of their mesenchymal nature, three groups were considered including control (culture medium only), differentiation (culture medium supplemented by basic fibroblast growth factor and epidermal growth factor), and treatment (culture medium and FBE). Growth curves as well as expression of glial fibrillary acidic protein (GFAP, marker for astroglial cells), galactocerebridase (GaLc, marker for 
oligodendrocyte and schwann cells), choline acetyl transferase (ChAT, marker for cholinergic neurons), and tyrosine hydroxylase (TH, marker of dopaminergic neurons) were examined in all the three groups at day 3 and 7 post-exposure. Also, nissl staining was performed in the three groups in order to assess protein synthesis and neurotransmitter production.

Results

Spindle-shaped cells were seen in the control group. There were neural-like cells in the differentiation group while more developed appearance with axon- and dendrite-like processes were present in the treatment group. To examine cell viability after exposure to FBE, growth curve was delineated. Higher proliferation rate and lower population doubling time were seen in the treatment group compared to other two groups. Regarding expression of neural markers, GaLC and ChAT at day 7 was prominent in the treatment group. Nissl bodies, which are rough endoplasmic reticulum, were seen only in the treatment group.

Conclusions

FBE might be a safer and more efficient inducer than combination of two wellknown growth factors in terms of differentiation of MSCs to functional dopaminergic neurons. Making neural cells in vitro is an attractive approach in improvement of injured nervous system. 
Keywords: mesenchymal stem cells; neural differentiation; fetal brain extract

\section{Background}

Stem cells have been given new hope to treat different kinds of diseases. Cell therapy, especially with the use of these cells, has been accepted as a promising therapeutic goal (1). Stem cells can differentiate into endodermal (e.g. hepatocytes) and ectodermal (e.g. neural cells) as well as mesodermal cell lineages (2).

In the nervous system, neural cells lose their function due to different reasons. Impairment of the nervous system, in turn, leads to other systems malfunction (3). The nervous system has limited ability to repair itself (1), and the current therapies have not contributed to a significant improvement in the disease status. On the other hand, Mesenchymal Stem Cells (MSCs) spontaneously express some neural markers, such as Nestin, c-Fos, and $\gamma$ enolase. This shows an intrinsic predisposition to differentiate into neural cells (4). Also, MSCs migrate toward injured sites and repair the affected tissues (5). Inherent potential of neurogenesis, axon growth stimulation, and generation of different types of neural cells from precursor ones have led researchers to use them in neurological disorders (6).

Differentiation of MSCs into the neural cells for substitution in affected tissues is a probably novel and efficient approach to resolve neurological disorders symptoms 
(7). In this context, chemical substances have been used for neural differentiation, which have resulted in satisfactory as well as unfavorable outcomes (8-11). For instance, use of growth factors solely or in different combinations has shown better outcomes (12). It is suggested that that the ideal method is to provide a condition similar to natural differentiation events in the body, which will be done by the presence of all necessary cytokines and chemokines. The clinical use of MSCs needs preclinical supplementary studies, especially in animal models (13). The present study aims to investigate the potential of fetal brain extract (FBE) as a physiologic inducer to promote neural differentiation in Bone Marrow-derived MSCs (BM-MSCs).

\section{Methods}

- Fetal brain extract preparation: This study is in accordance to institutional and national guidelines and regulations. Ethics committee in research at Shiraz University approved the experiments and confirmed that all experiments conform to the relevant regulatory standards. Rattus norvegicus were obtained from Animal House of Shiraz University of Medical Sciences, Shiraz, Iran. Light, temperature, and humidity were set according to the standard conditions for animal welfare and maintenance. The animals were fed with ordinary factory-made chow and water was available ad libitum. Pregnant rats at the late second week of gestation were transferred to the 
laboratory. Deep anesthesia was applied by ether and then, they were euthanized by cervical dislocation. All procedures were carried out in cold condition. The fetuses were taken out of the womb, their skulls were opened, and the whole brains were removed. Brains from all fetuses were homogenized and pooled. Dulbecco`s Modified Eagle Media (DMEM, Gibco, USA) was added to the suspension ( $1 \mathrm{ml}$ of DMEM per $150 \mathrm{mg}$ of suspension) and the mixture was centrifuged at $8600 \mathrm{~g}$ at $4^{\circ} \mathrm{C}$ for 10 minutes. The supernatant was considered as FBE and was kept at $-76^{\circ} \mathrm{C}$ until use.

- Establishment of BM-MSCs at passage III: Three male adult rats weighing 110-140g were chosen. They were euthanized using the method mentioned above. Femurs and tibias of both sides were taken out and floated in PBS enriched with $1 \%$ penestreptomycine. In this study, Complete Culture Medium (CCM) is considered as $88 \%$ DMEM, 10\% Fetal Calf Serum (FCS), $1 \%$ penestreptomycine, and $1 \%$ fungizone. Bone extremities were cut and flushed with DMEM. Flushing was done through both sides until the bone color changed from red to pale. Centrifugation was done at room temperature (1200rpm, 15min) and the supernatant was discarded. Then, 1 $\mathrm{ml}$ of CCM was added to the cell pellet and mixed. Afterwards, a T25 culture flask was filled with $5 \mathrm{ml}$ of CCM and the cell suspension was added 
to the flask. The flask was then transferred to a humidified incubator $\left(37^{\circ} \mathrm{C}\right.$, $5 \% \mathrm{Co}_{2}$ ). After 24 hours, the medium was removed, the cells were rinsed with PBS, and the flask was refilled with fresh CCM. After 10-12 days, the flask surface reached confluency. At this stage, the cells were passaged. The medium was discarded, the cells were rinsed with PBS, and one volume (approximately $3 \mathrm{ml}$ ) of Trypsin/EDTA $(0.25 \%)$ was added to the flask and kept in the incubator for 2-3 minutes. The flask was filled with two volumes of DMEM. Rinsing the culture surface repeatedly with this solution leaded to floating of the cells. Following centrifugation, $3 \mathrm{ml}$ of CCM was added to the cell pellet. Each $1 \mathrm{ml}$ of this cell suspension was added to a T75 flask that was prefilled with $15 \mathrm{ml}$ of CCM. Overall, three T75 flasks were kept in the incubator. This was called Passage 1 (P1). These procedures were done repeatedly until reaching $\mathrm{P} 3$.

- Characterization of BM-MSCs at passage III: A confluent T75 flask at P3 was prepared. The cells were harvested by Trypsin/EDTA treatment as mentioned before. After centrifugation, the cell pellet was subjected to total RNA extraction (Column RNA extraction kit, Dena Zist Asia, Iran). Absorbance ratio (A260/A280) and electrophoresis of RNA on agarose gel were performed to evaluate RNA quantity and quality. Subsequently, cDNA 
was synthesized, as well (Accupower cyclescript RT premix dN6, Bioneer, South Korea). Finally, Polymerase Chain Reaction (PCR) was carried out using the reagents of cinnagen company, Iran.

Table 1. Primer sequences of markers used in MSCs characterization

\begin{tabular}{lllc}
\hline Primer name & Forward primer & Reverse primer & \multicolumn{2}{c}{ Ampliqon size(bp) } \\
\hline CD34 & AGCCATGTGCTCACACATCA & CAAACACTCGGGCCTAACCT & 257 \\
CD45 & CCAAGAGTGGCTCAGAAGGG & CTGGGCTCATGGGACCATTT & 450 \\
CD73 & TGCATCGATATGGCCAGTCC & AATCCATCCCCACCGTTGAC & 208 \\
CD90 & GACCCAGGACGGAGCTATTG & TCATGCTGGATGGGCAAGTT & 177 \\
\hline
\end{tabular}

- Establishment of control, differentiation, and treatment groups at P3: When the cells at $\mathrm{P} 3$ reached about $70 \%$ confluency, the culture medium was removed and cells rinsed with PBS. Then, three flasks were assigned to three groups as follows: control group (C) only had DMEM, Treatment group (T) contained 80\% DMEM and 20\% fetal brain extract, and Differentiation group (D) had DMEM with basic Fibroblast Growth Factor (bFGF) and Epidermal Growth Factor (EGF) (final concentration of $0.01 \mathrm{ng} / \mu$ lit for each factor). All the flasks were transferred to the incubator $\left(37^{\circ} \mathrm{C}, 5 \% \mathrm{Co}_{2}\right)$.

- Growth curves: P3 was prepared in three 24-well plates. At 70\% confluency, the culture medium was substituted with specific media composition defined 
for each group (explained in previous step) with a modification (CCM was used instead of DMEM). After 24 hours, one well of each plate was considered, its medium was removed, and cells were rinsed with PBS, and then harvested from with Trypsin/EDTA treatment. After centrifugation, $1 \mathrm{ml}$ of CCM was added to the cell pellet. A certain volume of the cell suspension (e.g. $7 \mu$ lit) was mixed with the same volume of trypan blue stain. The whole mixture was placed on the neubauer slide and cells number was calculated using this formula: $\mathrm{T}_{1}=\mathrm{N} \times 2 \times 10^{4} \times \mathrm{V}$

$\mathrm{N}$ is the mean number of cells in four squares of the neubauer slide and $\mathrm{T}_{1}$ is the cell number for each well $(\mathrm{V}=1 \mathrm{ml})$. After calculating the cells number for two other wells $\left(\mathrm{T}_{2}\right.$ and $\left.\mathrm{T}_{3}\right)$, the mean of $\mathrm{T} 1, \mathrm{~T} 2$ and $\mathrm{T} 3$ was accounted as the cell number on the first day. These procedures were repeated for three groups for eight consecutive days.

- Expression of neural markers: Expression of neural markers was assessed at two time points. In this regard, two T75 flasks (for days three and seven) were prepared for each group at P3. At 70\% confluency, the cells were exposed to the group-specific culture media. They were harvested on designated days. Total RNA was extracted from the cell pellet (Rneasy plus 
Mini kit, Qiagen, Germany) and cDNA was synthesized

(Accupowercyclescript RT premix dN6, Bioneer, South Korea). Specific primers (Table 2) were used in PCR (Taq DNA Plymerase Master Mix Red, Ampliqon, Denmark).

Table 2. Primer sequences for neural markers

\begin{tabular}{lllc}
\hline Primer name & Forward primer & Reverse primer & Ampliqon size(bp) \\
\hline ChAT & GTCTGTGGAGTTTGCGGAAG & GATTGCTTGGCTTGGTTGG & 134 \\
GFAP & TTGAGTCGCTGGAGGAGGAG & GCTGTGAGGTCTGGCTTGG & 130 \\
GaLC & ACTGGAACTGGAGGAGGATG & AGGGCTGTGACTTGGGAG & 92 \\
TH & CAGCAGCAGCAGCGGTAG & CAGCATTCCCATCCCTCTCCT & 81 \\
\hline ChAT, choline acetyl transferase; GFAP, glial fibrillary acidic protein; GaLc, &
\end{tabular}

ChAT, choline acetyl transferase; GFAP, glial fibrillary acidic protein; GaLc, galactocerebridase; $\mathrm{TH}$, tyrosine hydroxylase.

- Nissl staining: Cells at P3 were established in three 6-well plates. After seven days, the medium was discarded and the cells were treated with $70 \%$ ethanol. Then, the cells were rinsed with $\mathrm{dH}_{2} \mathrm{O}$, exposed to giemsa stain, and kept in an incubator at $60^{\circ} \mathrm{C}$ for two hours. The cells were rinsed with $\mathrm{dH}_{2} \mathrm{O}$ again and were decolorized with $0.5 \%$ acetic acid. At the end, they were fixed with $96 \%$ and $100 \%$ ethanol, respectively. Images were captured via an invert microscope. 


\section{Results}

- Extraction of MSCs from BM: Given BM contains different types of cells, diverse morphologies were seen at P0 (Fig 1). This condition changed at P1 and the following passages. The majority of the cells showed spindle-shaped or fibroblastic-like forms. However, there were still some cells with different morphologies (Fig 2).

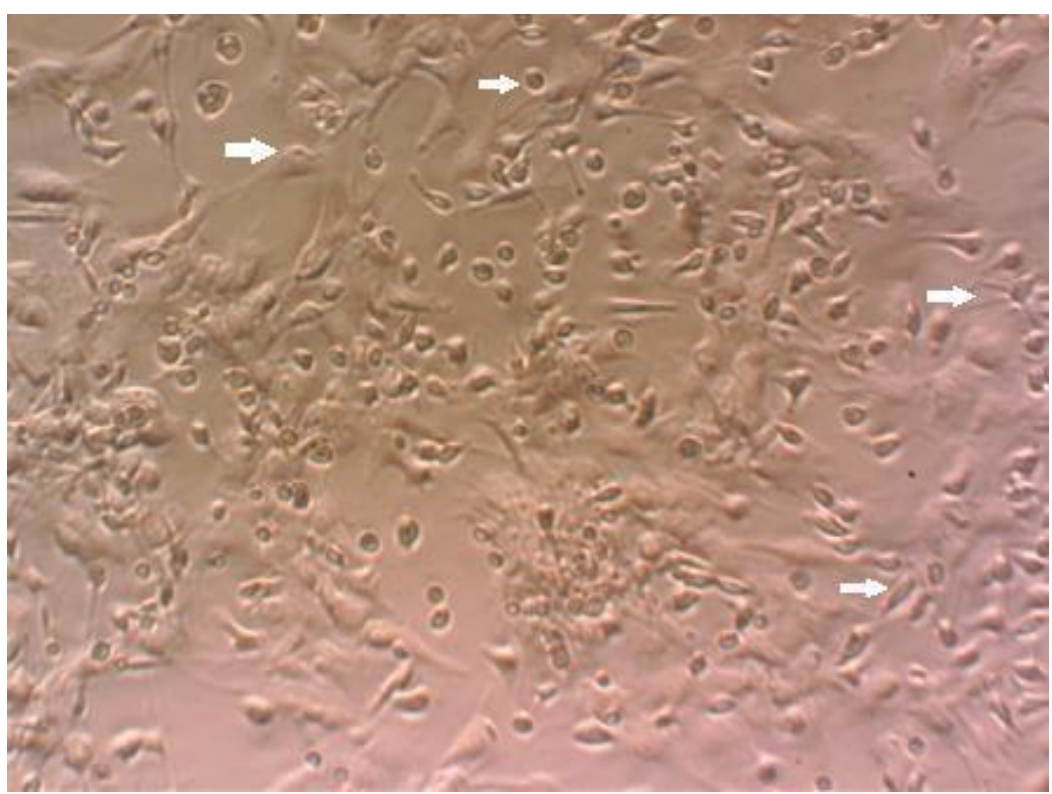

Figure 1. Cells at P0. Cells with different with morphologies such as round, flattened, or spindleshaped. 


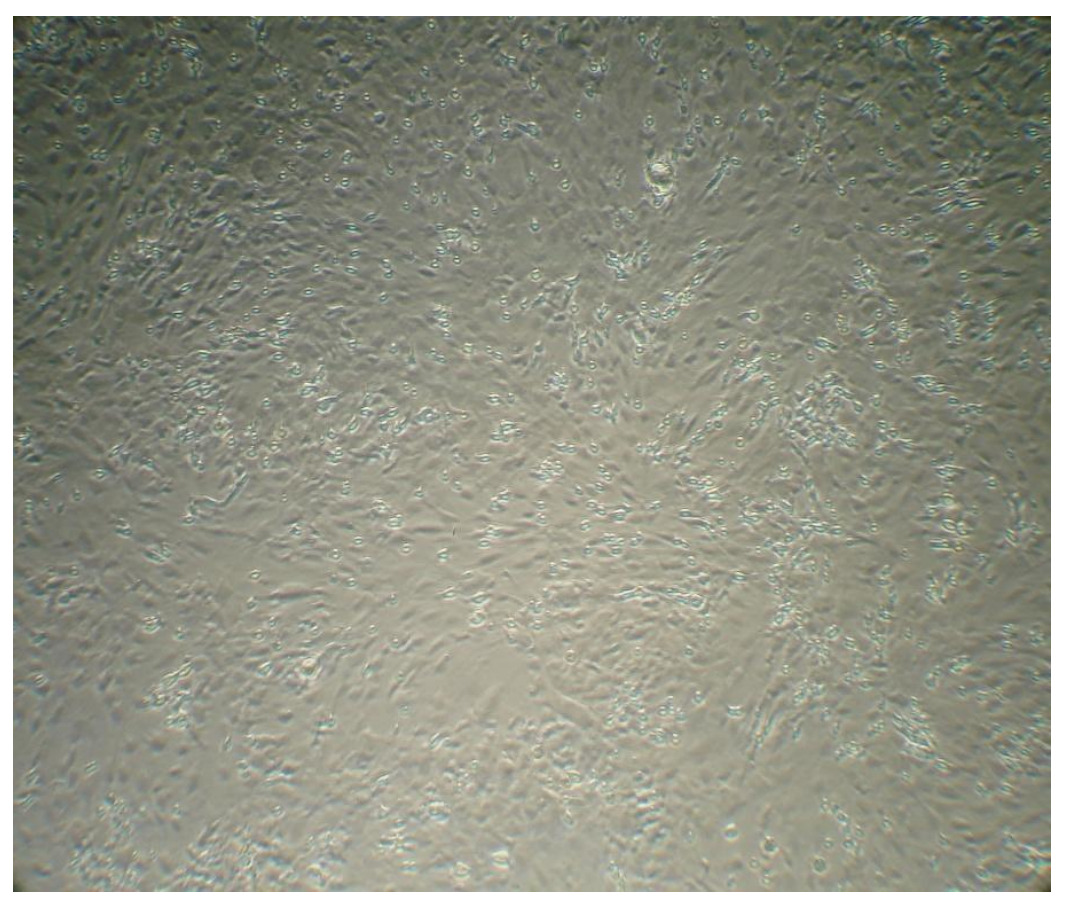

Figure 2. Cells at P3. The majority of cells showed spindle-shaped or fibroblastic morphologies, typical of MSCs.

- Characterization of BM-MSCs: The presence of MSCs' specific markers was checked. Because a substantial portion of cells in the BM have hematopoietic origin, it had to be determined whether the cultured cells at P3 resulted solely from MSCs proliferation or not. Thus, absence of hematopoietic specific markers was evaluated. In so doing, expression of hematopoietic progenitor cell antigen (CD34), protein tyrosine phosphatase (CD45), 5' nucleotidase (CD73), and Thy-1 cell surface antigen (CD90) was sought (Figure 3). 


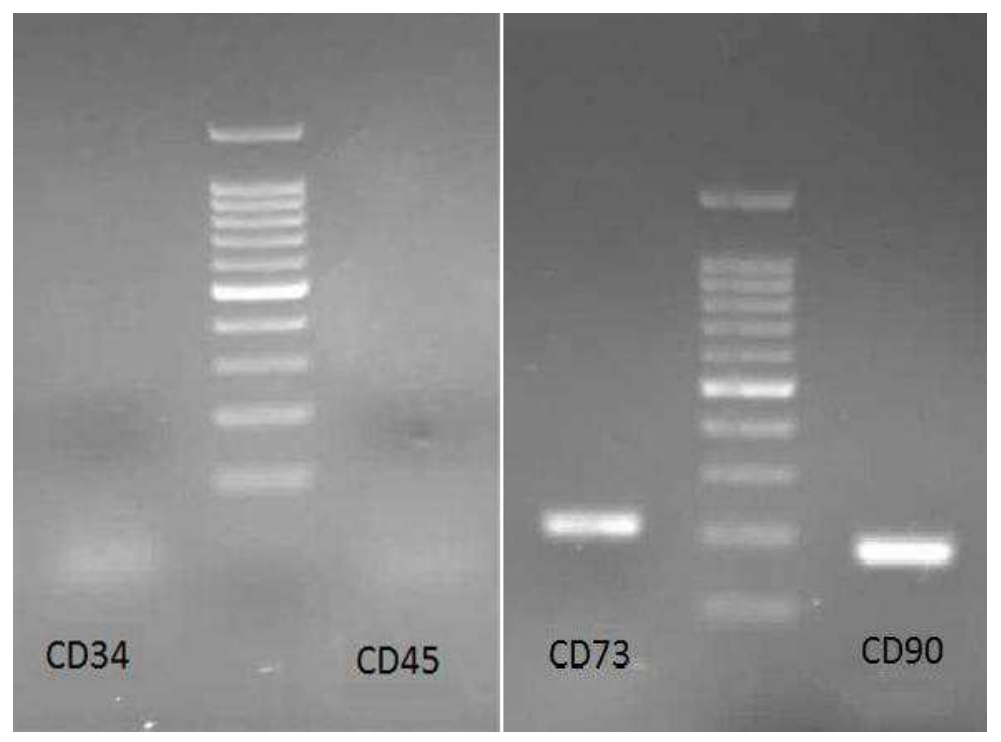

Figure 3. Characterization of MSCs at P3. Left: absence of CD34 (257bp) and CD45 (450bp). Right: presence of CD73 (208bp) and CD90(177bp). Ladders were 100bp.

- Morphology of the cells on day 3 (post-treatment): Diverse morphologies, including spindle shape and round shape, were seen in the group C. This group showed a low rate of proliferation, which was the result of lower cell density (Figure 4). 


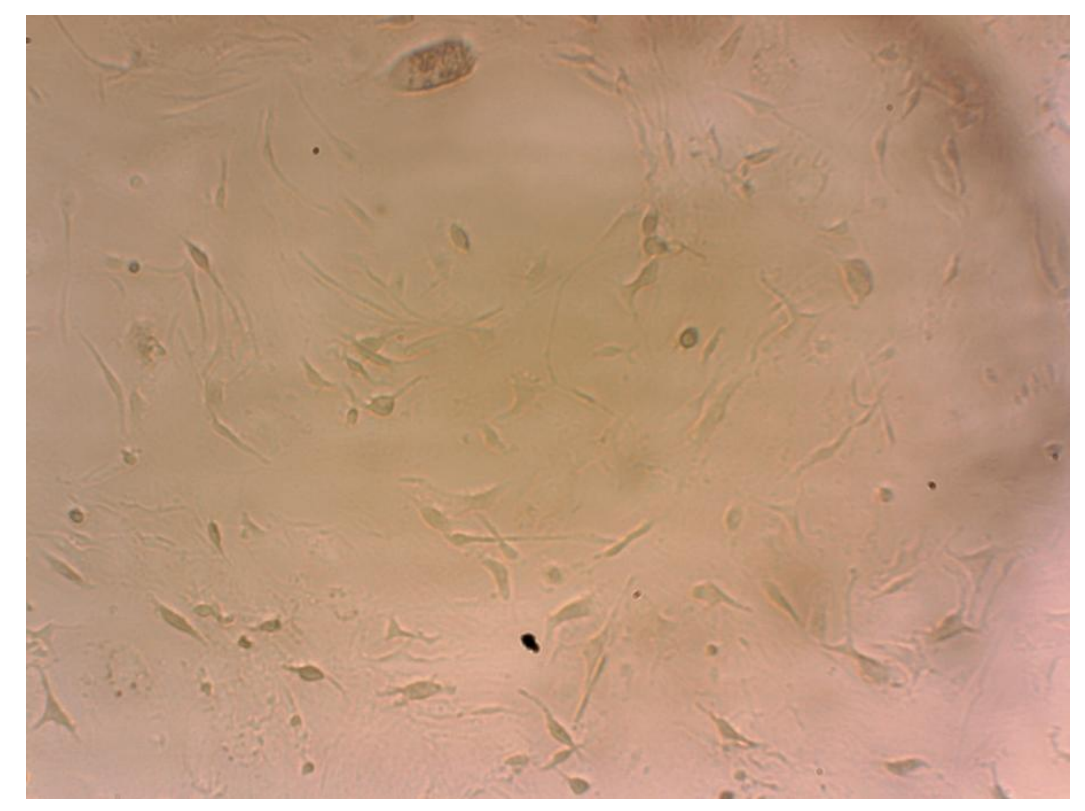

Figure 4. Cells in the group $\mathrm{C}$ on day 3. Arrows show spindle-shaped morphology.

Majority of cells in group D still showed spindle-shape morphology with higher cell density compared to group C (Fig 5).

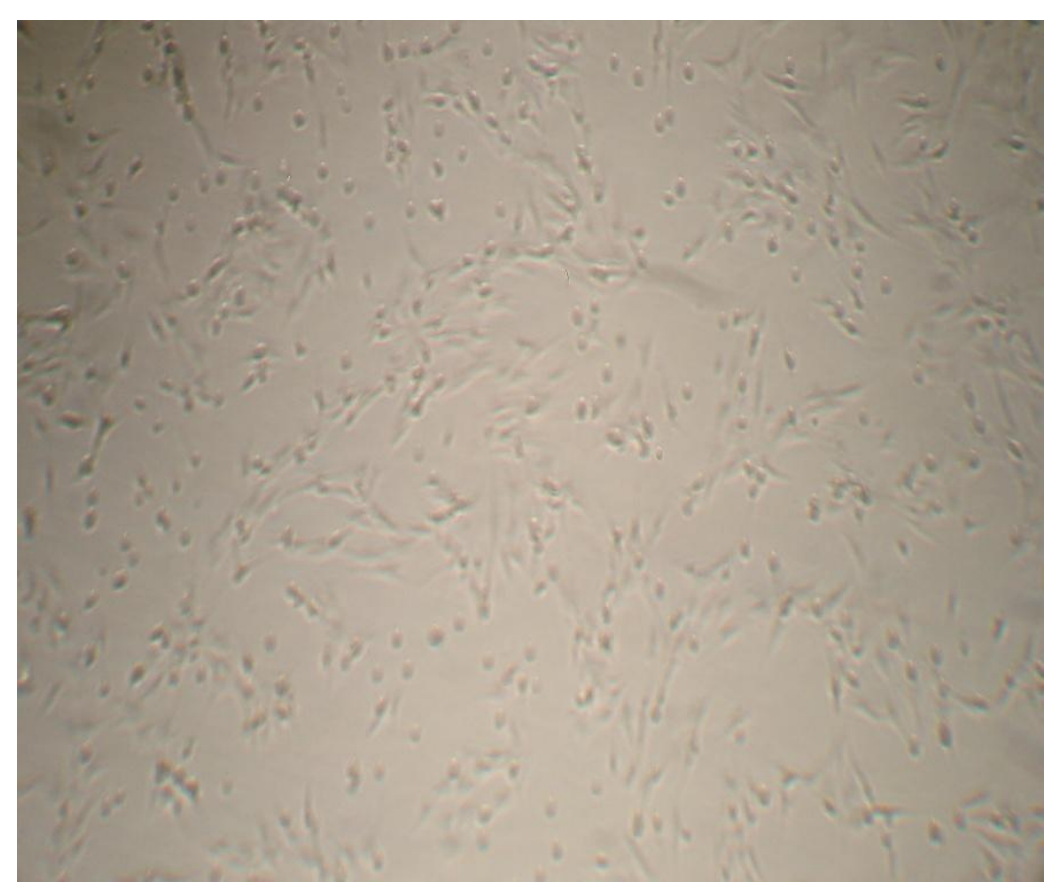

Figure 5. Cells in the group $\mathrm{N}$ on day 3. 
In the group $\mathrm{T}$, cells with axon and dendrite-like processes with $2,3,4$, or even more branches had increased remarkably. Moreover, some cells had distinct elongated processes. Furthermore, cell density was higher in comparison to the group D (Fig 6).

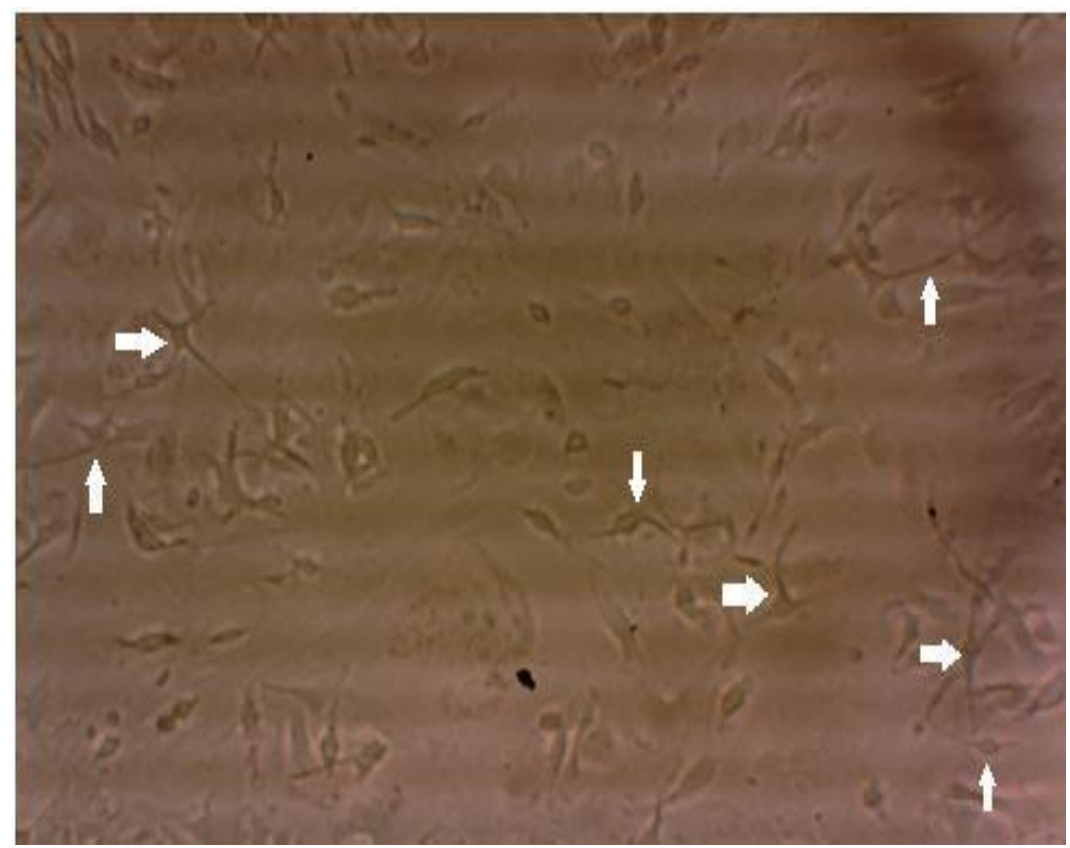

Figure 6. Cells in the group T on day 3. Cells with neural-like morphology were increased.

- Morphology of the cells on day 7 (post-treatment): Flattened and round cells were dominant in the group C at day 7. Dead cells were floated in the culture medium. There were also cells with some projections. As the appearance of these cells was not seemed healthy, the existence of projections might be related to cell shrinkage or cytoskeletal destruction. There was no significant difference in this groups' cell density on days three and seven (Fig 7). 


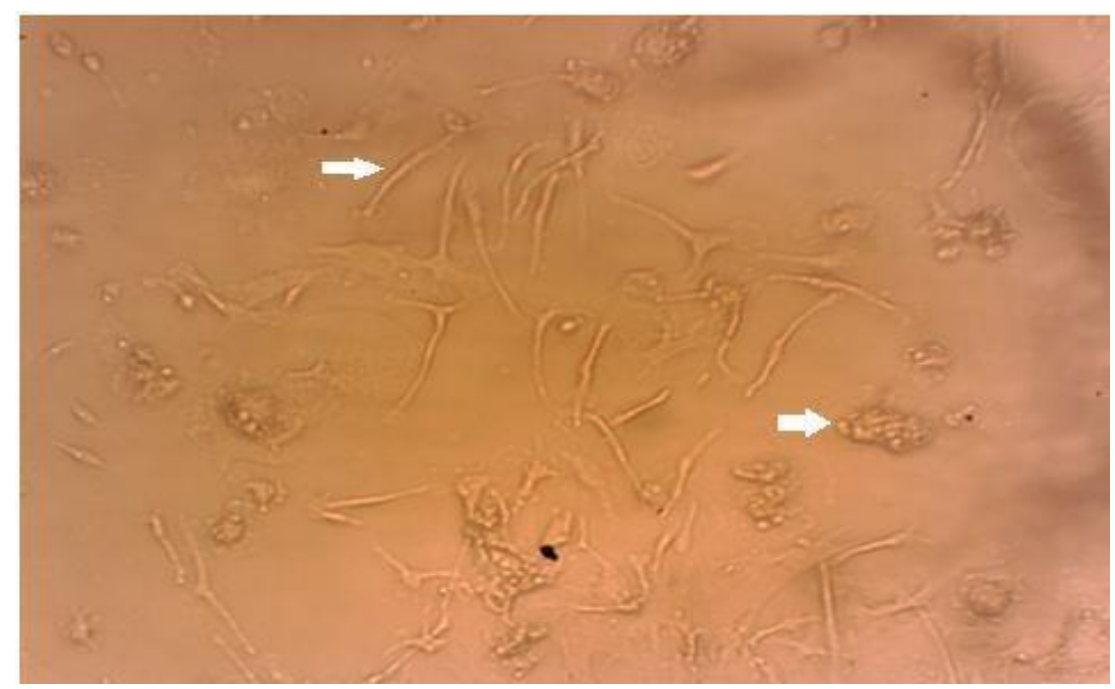

Figure 7. Cells in the group $\mathrm{C}$ on day 7. Dead and unhealthy cells were shown.

In the group D, the number of spindle-shaped cells was more than the other forms. Aggregation of cells with elongated processes was also seen in some fields (Fig 8).

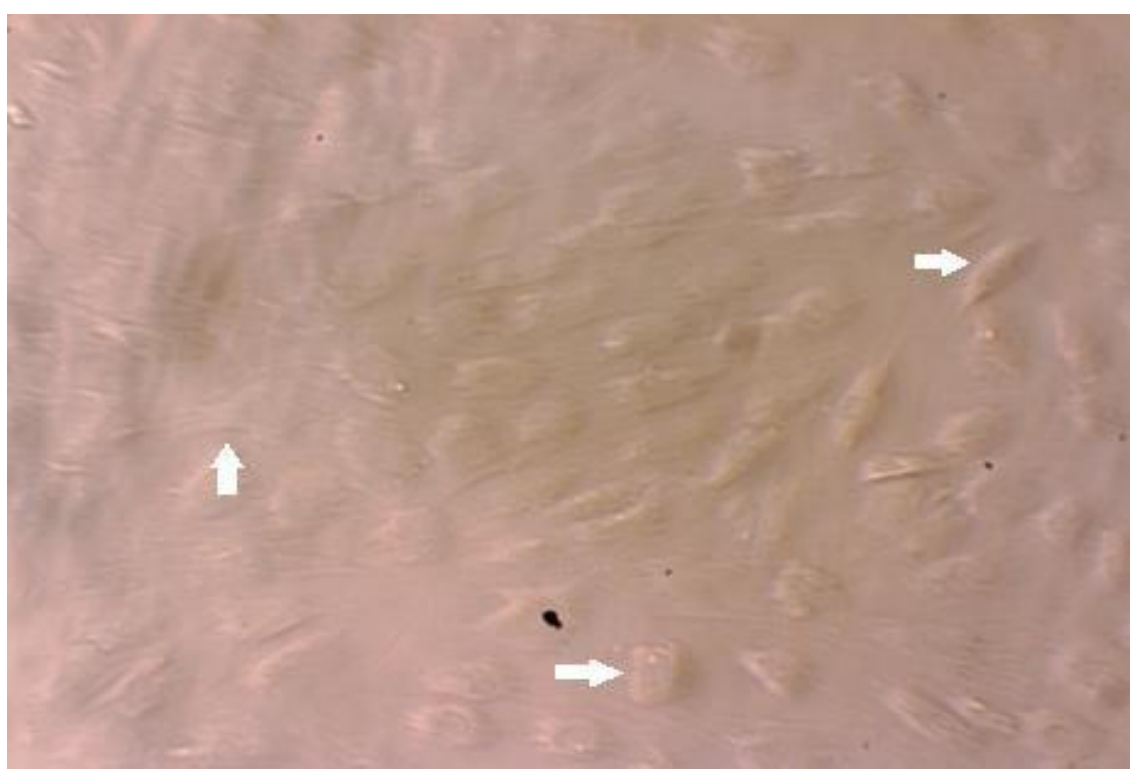




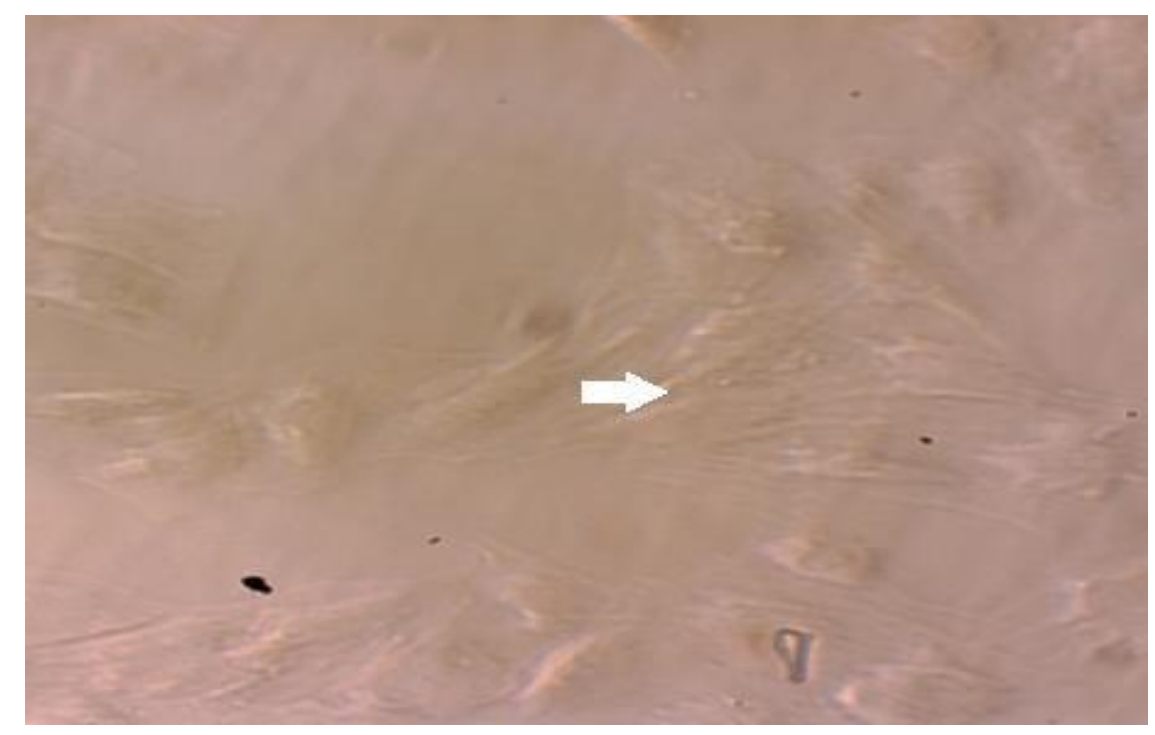

Figure 8. Cells in the group D on day 7. Upper: prevailing of spindle-shaped cells. Down: cells with elongated processes.

Neural-like morphology were prominent in the group $\mathrm{T}$ at day 7 . Indeed, the processes became more developed. These processes were short in some cells, but long in some others. Spindle-shaped and flattened cells were seen, as well (Fig. 9).

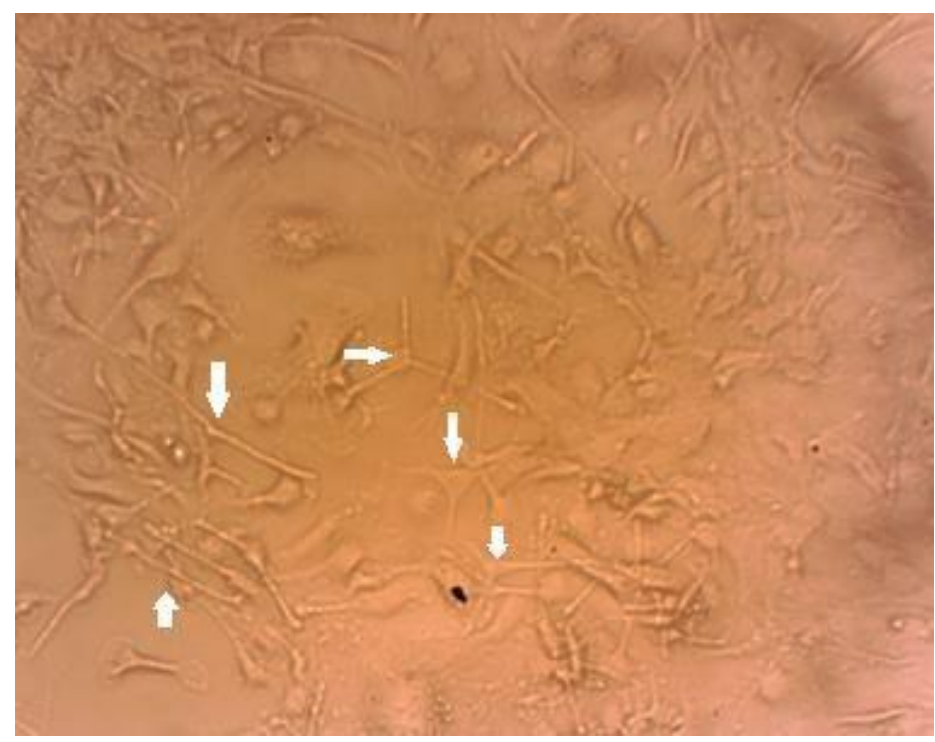



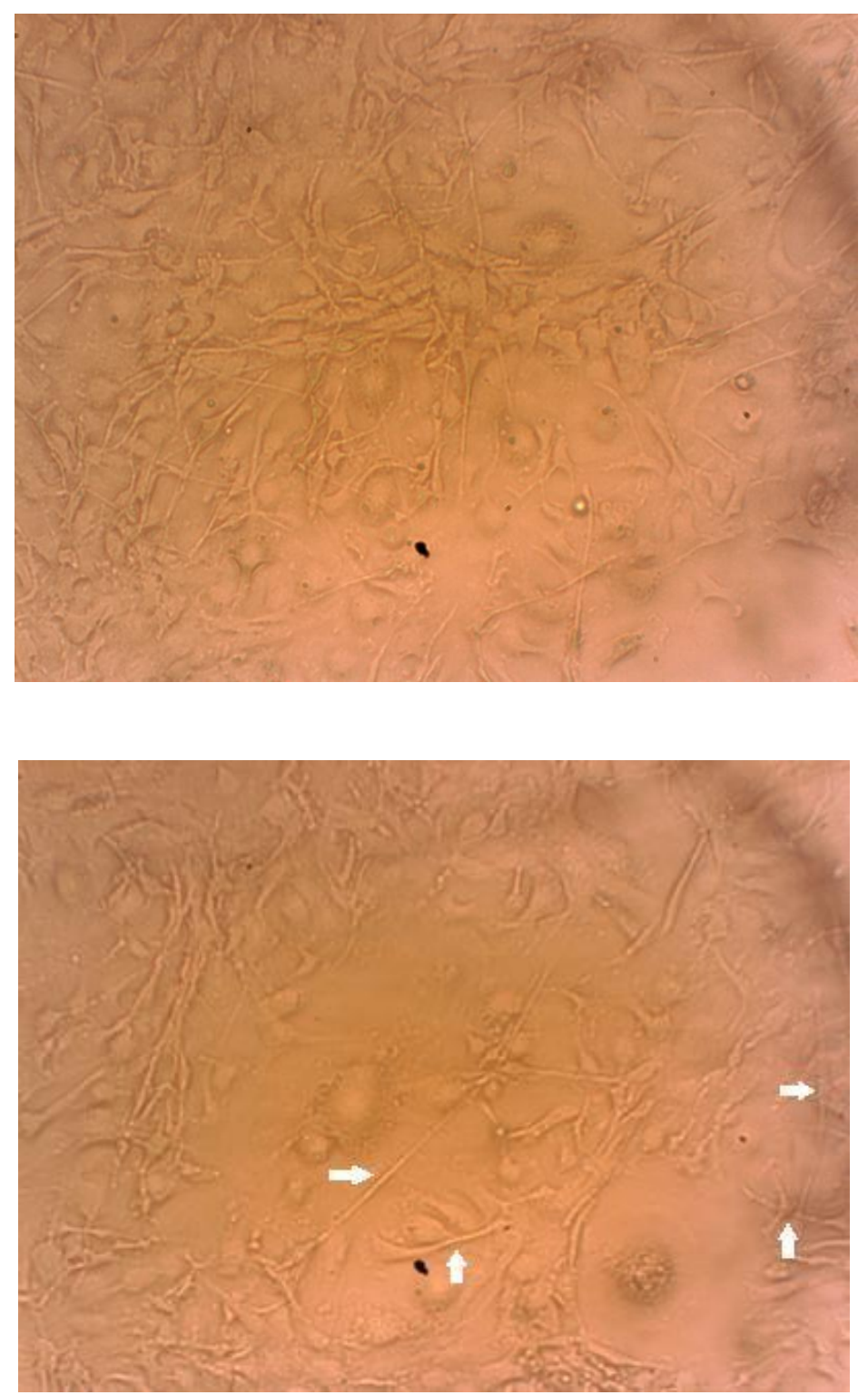

Figure 9. Cells in the group $\mathrm{T}$ on day 7. Upper: neural-like cells with developed processes.

Middle: aggregation of cells with neural-like morphology. Down: forming of long branches was considerable in some cells. 
- Growth curves: In order to evaluate the effect of FBE on cell viability, growth curves were considered and the results have been presented in Figure 10.

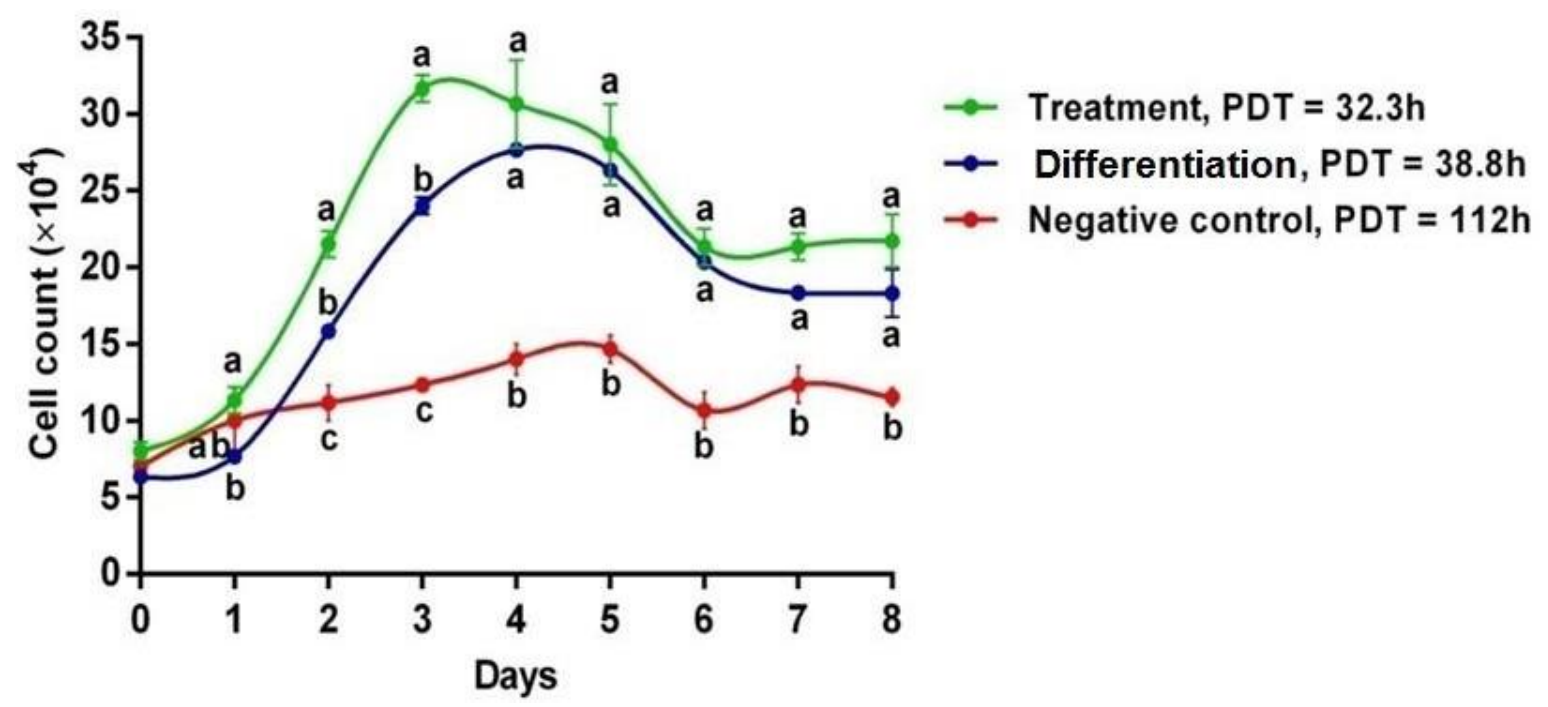

Figure 10. Growth curves of cells throughout the eight days

A similar trend was governed in all groups, but with some differences in details. After a lag phase, the proliferation phase emerged. Cells in the group $\mathrm{C}$ grew until day 5, while this occurred in a faster manner and a shorter time period in the groups $\mathrm{T}$ and $\mathrm{D}$. Thus, the saturation state was reached by day 4 in group $\mathrm{D}$ and by day 3 in group T. Simply, this showed that the proliferation rate was higher in the group T compared to the group D. After that, the cells number commenced to 
decrease in the three groups and the plateau phase was observed (Fig. 10). Another factor used to evaluate the growth rate was the time spent for cell doubling. This was called Population Doubling Time (PDT), which was calculated using the following formula:

$\mathrm{PDT}=\mathrm{T} \times \ln 2 / \ln \left(\mathrm{X}_{\mathrm{e}} / \mathrm{X}_{\mathrm{b}}\right)$

$\mathrm{T}$ : incubation time in hours

$\mathrm{Ln}=\log _{\mathrm{e}} \quad \mathrm{e}=$ neper number

$\mathrm{X}_{\mathrm{e}}$ : cell number at the end of the incubation time

$\mathrm{X}_{\mathrm{b}}$ : cell number at the beginning of the incubation time

The data were entered in to the SPSS statistical software, version 16 and were analyzed using one-way ANOVA and Tukey's post-hoc test. According to the results, PDT was $112,38.8$, and 32.3 hours in the N, D, and T groups, respectively.

- Expression of neural markers: Signatures of GFAP as a specific marker of astroglial cells (14) and GaLc as a specific marker of oligodendrocytes and schwann cells (2) were sought. Expression of ChAT and TH as the identifiers of cholinergic and dopaminergic neurons, respectively $(15,16)$ was also assessed. Moreover, PCR products of the T group were sequenced in order to ensure about the identity of ampliqons. 
GFAP expression was not significant in the study groups on days 3 and 7 . However, a footprint might be detectable in the group $\mathrm{D}$ and even in the group $\mathrm{T}$ at the second time point (Fig. 11).
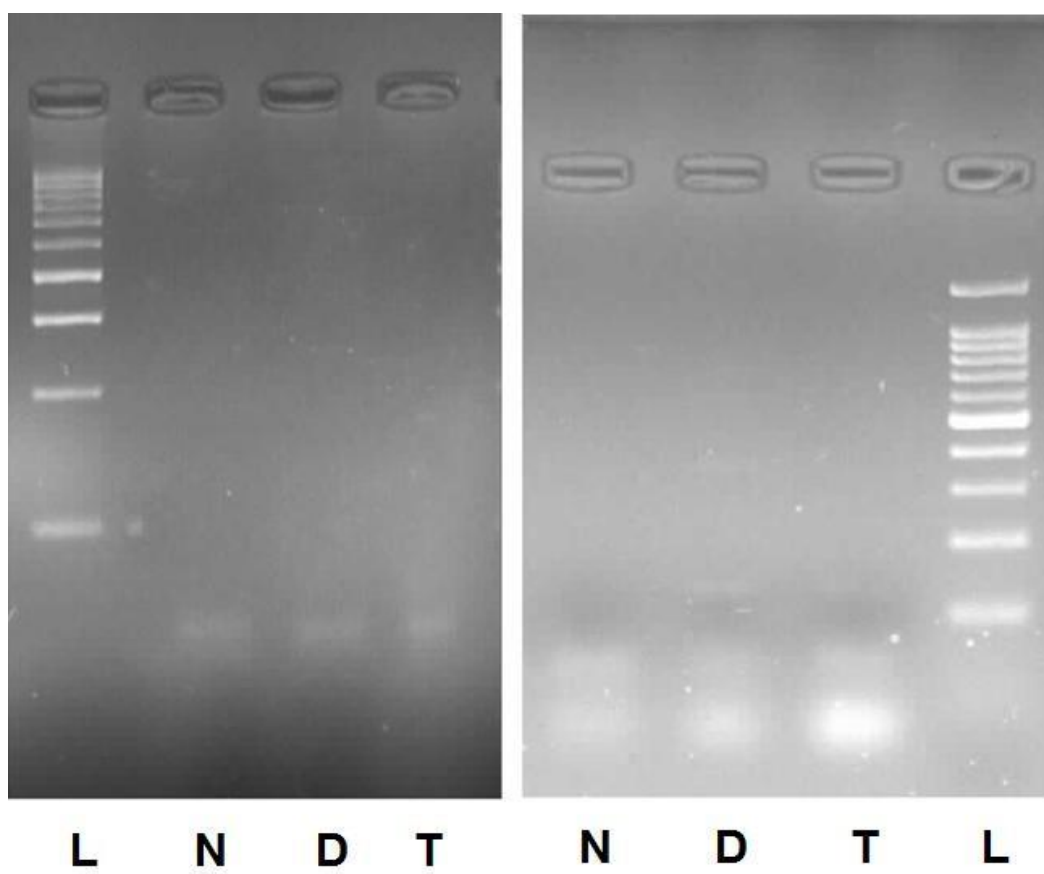

Figure 11. Left and right: GFAP (130 bp) expression pattern on days 3 and 7, respectively. L:

$100 \mathrm{bp}$ ladder. N, D, and T stands for negative control, differentiation, and treatment groups.

On day 3, expression of GaLC in the group $\mathrm{T}$ was approximately equal to that in the group $\mathrm{D}$ and both were higher compared to the group N. It seems that this marker was considerably expressed in the group $\mathrm{T}$ compared to the two other groups on day 7 (Fig. 12). 


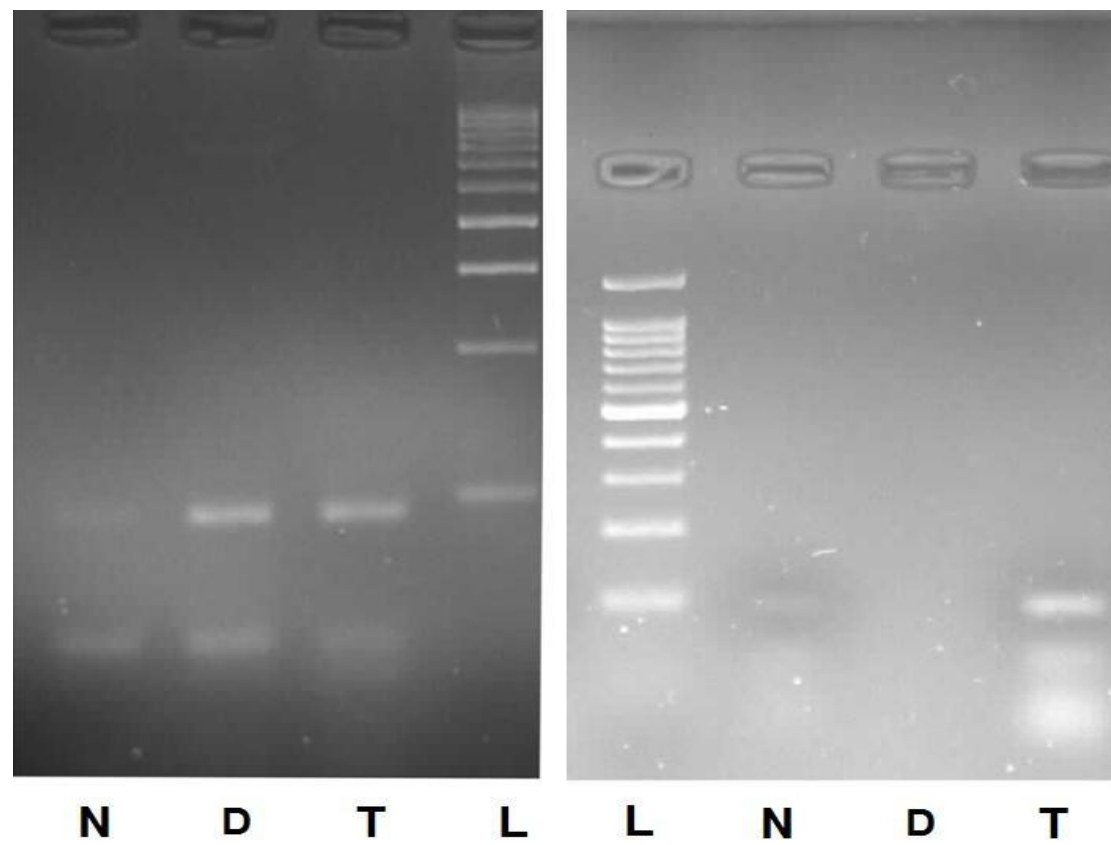

Figure 12. Left and right: GaLC (92 bp) expression pattern on days 3 and 7, respectively. L: 100 .bp ladder. N, D, and T stands for negative control, differentiation, and treatment groups

ChAT was not expressed in the group T on day 3. Nonetheless, some traces existed in the groups $\mathrm{D}$ and $\mathrm{N}$. Its expression in the T group was notable and nearly similar to that in the group D on day 7 while no bands were observed in the group N (Fig. 13). 


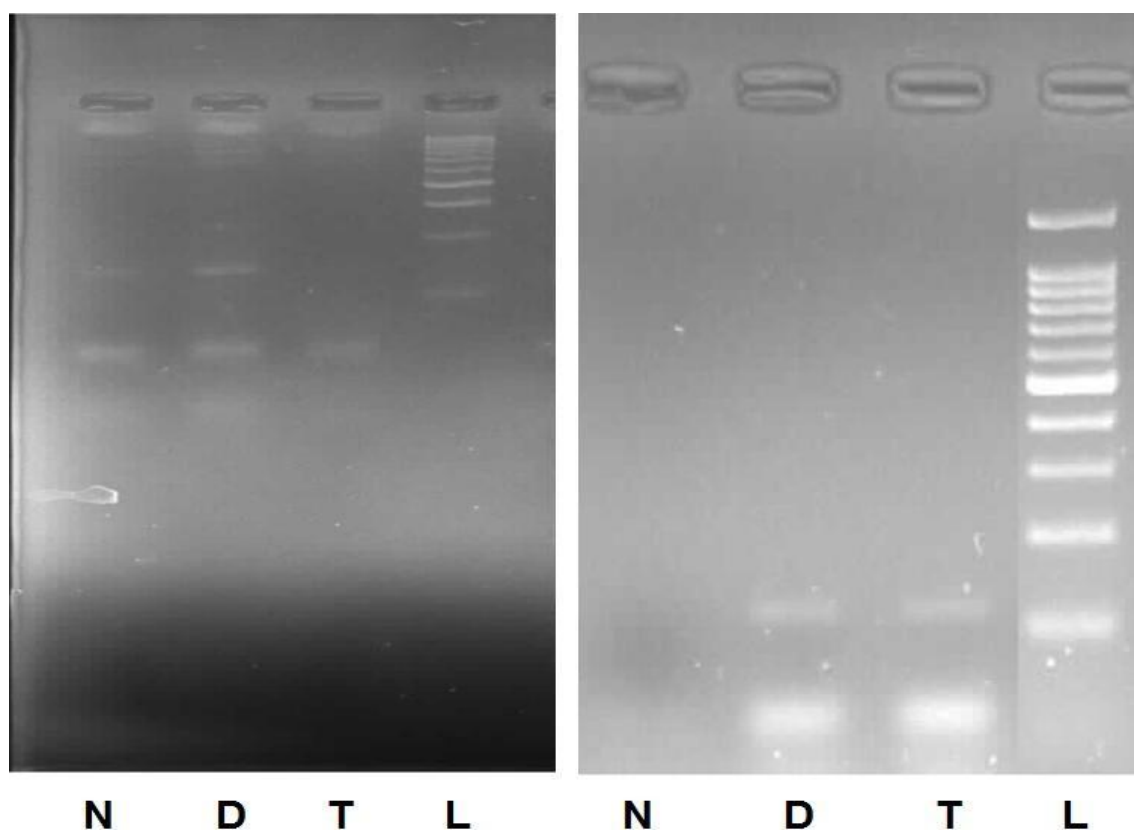

Figure 13. Left and right: ChAT (134 bp) expression patterns on days 3 and 7, respectively. L: $100 \mathrm{bp}$ ladder. N, D, and T stands for negative control, differentiation, and treatment groups.

TH expression was lower in the group $\mathrm{T}$ in comparison to groups $\mathrm{D}$ and $\mathrm{N}$ on day 3. Although it became higher than that in the group $\mathrm{N}$ on day 7 , it was still lower compared to group D. 

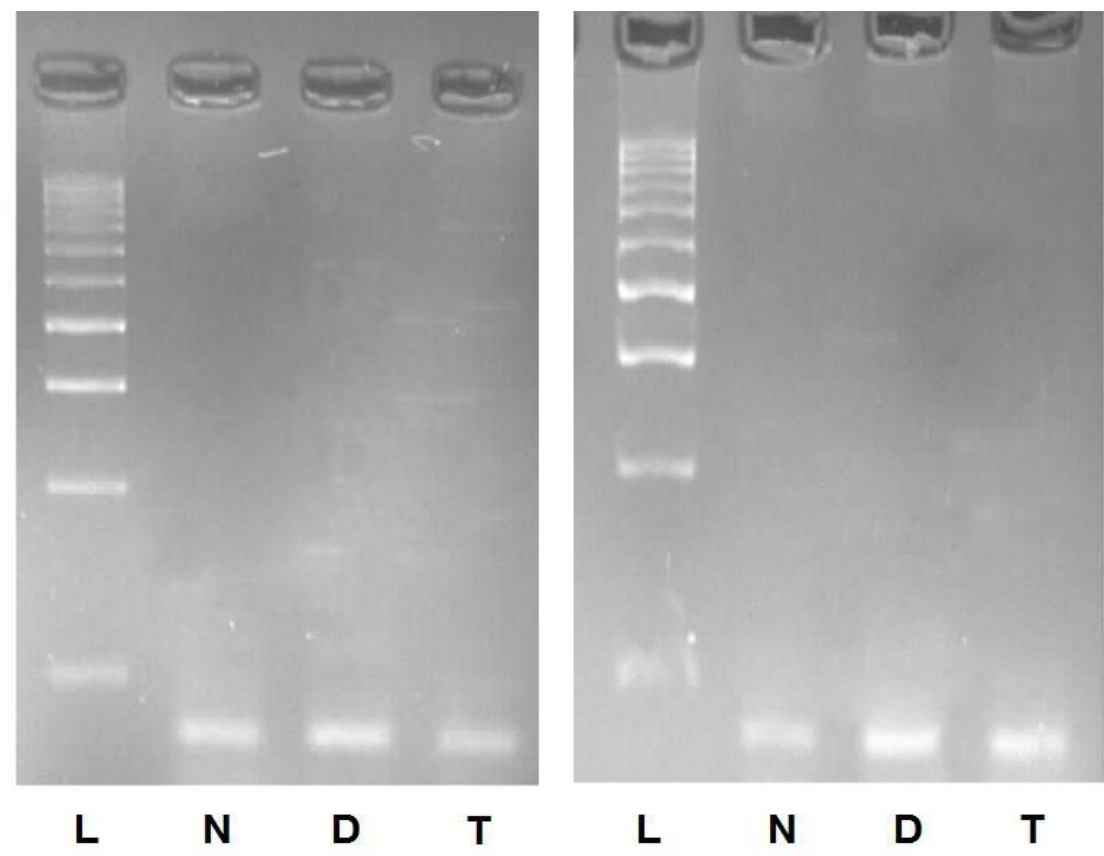

L $\quad$ N $\quad$ D $\quad$ T

Figure 14. Left and right: TH (81 bp) expression patterns on days three and seven, respectively.

L: 100 bp ladder. N, D, and T stands for negative control, differentiation, and treatment groups.

- Nissl staining: Nissl bodies were seen only in the group T. This was confirmed by an expert histopathologist who was blinded to the samples (Fig. 15, 16, 17). 


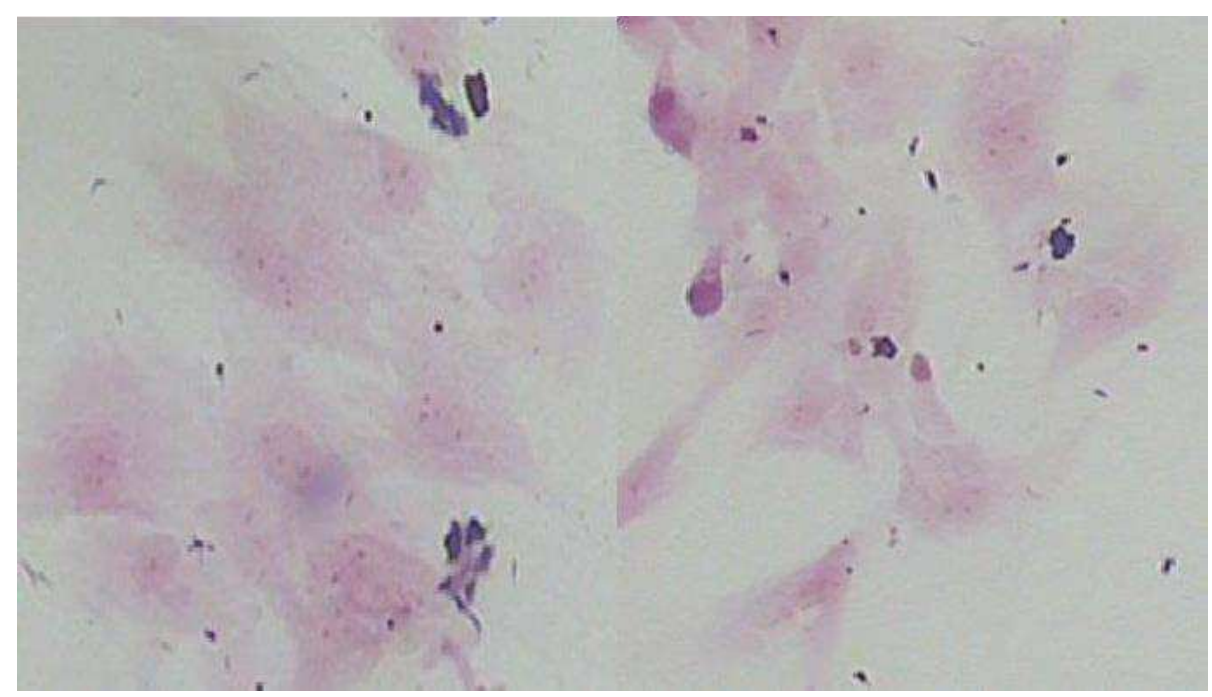

Figure 15. The group C

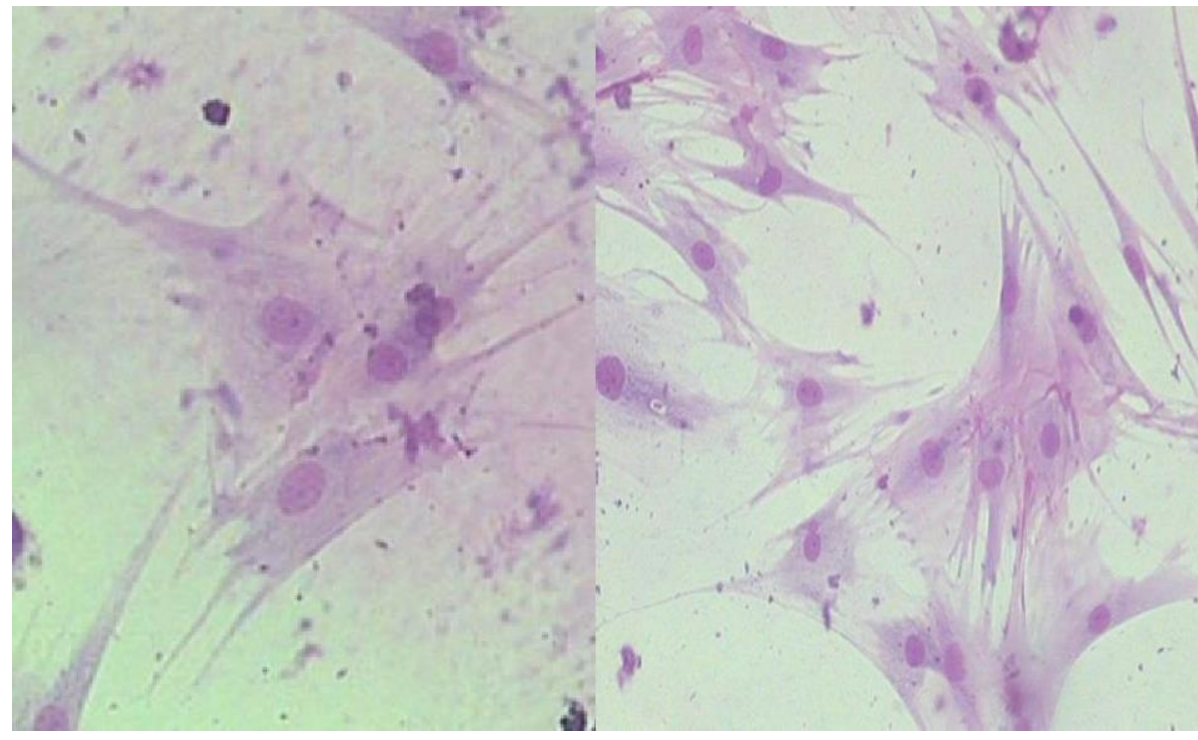

Figure 16. The group D 


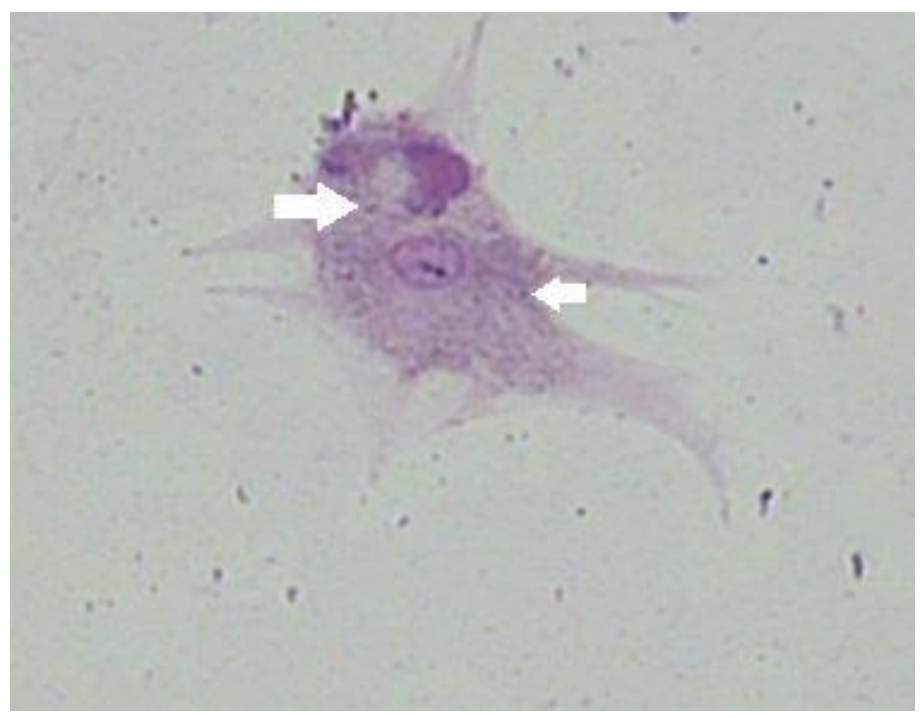

Figure 17. The group T. Arrows point at Nissl bodies.

\section{Discussion}

To the best of our knowledge, no unique marker has been available to characterize MSCs identity yet. Therefore, a pattern of markers expression and inexpression was sought. According to the results, presence of mesenchymal markers and absence of hematopoietic ones were confirmed by RT-PCR. A few days after being in P0, fibroblastic-like or spindle-shaped cells as the typical morphology of MSCs were dominated. As no other growth stimulators than DMEM was present, low density of cells in the group C was not an unexpected event. On the other hand, cell density was higher in the group D due to employment of two growth factors in addition to the DMEM. Proliferative capability of EGF beside neural 
differentiating potential of bFGF could be effective in this regard (16). Interestingly, the highest cell density belonged to the $\mathrm{T}$ group. This indicated that FBE was more potent even than the combined effect of the two stimulators in terms of cell multiplication. Additionally, the highest and lowest cell counts belonged to $\mathrm{T}$ and $\mathrm{N}$ groups, respectively. This implies that the FBE did not induce cell death. Besides, based on growth curve analysis and PDT, the medium in the group T provided better circumstances for growth.

From the neural differentiation perspective, the $\mathrm{T}$ group gained a better position. It had an obviously larger number of neural-like cells both on days 3 and 7. Indeed, this type of morphology was more mature and developed considering cell processes. It should be noted that a similar morphology, but in a lower number and with less-developed branches, was seen in the group D. There were no neural-like cells in the $\mathrm{C}$ group in neither time points. Expression of GaLC at two time points showed that FBE not only moved MSCs forward to the oligodendrocyte phenotype, but it was a more stable inducer than EGF and bFGF during this time course.

Expression of ChAT and $\mathrm{TH}$ as respective determinants of functionality of cholinergic and dopaminergic neurons was assessed in the present study. The findings showed that cholinergic neurons were present in the T group, especially on day seven, while this was not the case in the $\mathrm{C}$ group. On the other hand, 
although there were footprints of dopaminergic neurons in the T group on day 3 , expression of this marker was much more significant after 7 days. It seems that treatment of MSCs with FBE during 7 days yielded neural-like cells at a detectable level. This finding was in accordance with the presence of nissl bodies in the $\mathrm{T}$ group. Nissl bodies are rough endoplasmic reticulum in neurons, which are responsible for protein synthesis and neurotransmitter production. Such tiny dark cytoplasmic granules were not found in the $\mathrm{C}$ and $\mathrm{D}$ groups (16).

Some chemical agents like beta-mercaptoethanol promote MSCs toward neurons in a faster manner compared to EGF and bFGF $(17,18)$. However, some evidences have shown that these compounds negatively affected the cells viability via induction of apoptosis, toxic effects, shrinkage, and destruction of actin skeletal structures $(8,10,11,19)$. Woodbury et al. (18) reported that MSCs could change into neural-like cells after exposure to EGF and bFGF and expressed a significant amount of neural markers, such as nestin, beta III tubulin, and Microtubule Associated Protein (MAP2) (20). Similarly, Sanchez-Ramos et al. applied retinoic acid and brain-derived neurotrophic factor (BDNF) to MSCs. They found signatures of neural cells when neural markers, such as NeuN and GFAP, were expressed in some cells (21). In another experiment, treatment of human MSCs with three different growth factors produced undifferentiated neural cells (15). In a study, expression of MAP2, GFAP, and NeuN was detected in MSCs treated with 
CART peptide. Based on the results, TH and ChAT were expressed and Nissl bodies were seen in their cytoplasm. It was believed that the peptide stimulated the endogenous expression of the nerve growth factor and BDNF. In other words, it provided a somewhat similar situation to the natural neural differentiation pathways in the brain (16). It is believed that better performance of growth factors is due to their mechanistic similarities with natural chemokines and cytokines in the body.

Previous studies evaluated the differentiation of MSCs toward neural lineage using the extracts of different parts of the nervous system as the inducer. For instance, treatment of MSCs with soluble portions of brain cortex, cerebellum, and hippocampus resulted in formation of bipolar and multipolar cells (6). Additionally, the injured brain extract accelerated the differentiation of fetal stem cells compared to the control group. Another investigation revealed a decrease in Oct-4 expression as a marker for stemness and an increase in nestin and MAP2 expression as markers of neural cells over 3 days. However, cell loss occurred due to apoptosis (22). In another study, MSCs derived from human umbilical cord blood were cultured in the presence of the brain tissue extract. These cells acquired a morphology similar to that of neural cells (23). Also, brain tissue extract was used in order to advance omental stem cells toward neural lineage. It was argued that the brain extract constituted nerve growth factor, BDNF, and 
neurotrophine3/4, which could progress neural cells formation (24).

Nowadays, diverse approaches, including medical and surgical therapies, have not been able to resolve neurological disorders satisfactorily. Neuron transplantation meaning substitution of malfunctioned neural cells with functional ones has become a prominent solution. Making neural cells in vitro and applying them in vivo in order to retrieve the lost capability is very attractive. To reach this goal, two issues are important; first, the type of the precursor cell from which neural cells should be originated and second, the type of inducer for neural differentiation. Characteristics of BM-MSCs have made these cells novel candidates for playing the role of precursors. These advantages include the feasibility of autologous cell source, easiness of proliferation and expansion in culture media compared to other adult stem cells, and lack of concerns about ethical issues as opposed to fetal stem cells.

Experiments have also shown the positive therapeutic effects of MSCs in neural disorders, such as Huntington's and Parkinson's diseases, via secretion of neurotrophines and anti-inflammatory cytokines (25). After transplantation of these cells into the brain in rodents or humans, they could differentiate into diverse neural cells (hippocampus, cerebral cortex, cerebellum, olfactory bulb, etc.) (26, 27). 
As development of neural cells is completed before birth, whole brain-derived extract at the fetal stage was used in the present study to take its advantages for neural differentiation. Incomplete process of differentiation might have some benefits in comparison to the complete one. Stem cells that had passed the initial steps of differentiation had a much lower risk of tumorigenesis compared to preliminary stem cells (28).

\section{Conclusions}

Although efforts are being made to generate mature functional neural cells in laboratory settings, development of a fast, simple, and inexpensive method should be considered as a priority. In this regard, it is necessary to draw a clear picture of molecular and physiologic mechanisms for neural cells' generation while available models have not yielded an acceptable number of viable and differentiated cells while reliance on endogenous repertoire of MSCs does not gain desirable outcome.

\section{List of abbreviations}

BM-MSCs: bone marrow-derived mesenchymal stem cells; FBE: fetal brain extract 


\section{Declarations}

Ethics approval and consent to participate: The present study is in accordance to the declaration of Helsinki and has approved by the Ethical Committee of Shiraz University.

Consent for publication: Not applicable

Availability of data and materials: The datasets used and/or analysed during the current study are available from the corresponding author on reasonable request.

Competing interests: The authors declare that they have no competing interests.

Funding: This work was financially supported by Shiraz University. The funding body had no role in the design of the study and collection, analysis, and interpretation of data and in writing the manuscript.

Authors' contributions: MMGS contributed substantially to the concept and design of the study. IRJ and SZ acquired the data. IRJ, DM, AM, MJZ, and AM had roles in data analysis and interpretation. IRJ drafted the manuscript. All authors read and approved the final manuscript.

Acknowledgements: The authors would like to thank Ms. A. Keivanshekouh at the Research Improvement Center of Shiraz University of Medical Sciences for improving the use of English in the manuscript. 


\section{References}

1. Moore T, Abrahamse H. Neuronal Differentiation of Adipose Derived Stem Cells: Progress So Far. International Journal of Photoenergy. 2014;2014.

2. Bae KS, Park JB, Kim HS, Kim DS, Park DJ, Kang SJ. Neuron-like differentiation of bone marrowderived mesenchymal stem cells. Yonsei medical journal. 2011;52(3):401-12.

3. Sarlak G, Jenwitheesuk A, Chetsawang B, Govitrapong P. Effects of melatonin on nervous system aging: neurogenesis and neurodegeneration. Journal of pharmacological sciences. 2013;123(1):9-24.

4. Karaoz E, Aksoy A, Ayhan S, Sarıboyacı AE, Kaymaz F, Kasap M. Characterization of mesenchymal stem cells from rat bone marrow: ultrastructural properties, differentiation potential and immunophenotypic markers. Histochemistry and cell biology. 2009;132(5):533-46.

5. Ma S, Xie N, Li W, Yuan B, Shi Y, Wang Y. Immunobiology of mesenchymal stem cells. Cell Death \& Differentiation. 2014;21(2):216-25.

6. Rivera FJ, Couillard-Despres S, Pedre X, Ploetz S, Caioni M, Lois C, et al. Mesenchymal stem cells instruct oligodendrogenic fate decision on adult neural stem cells. Stem Cells. 2006;24(10):2209-19.

7. Mehranjani MS, Chian MF. Cysteine: A Novel Neural Inducer for Rat Bone Marrow Mesenchymal Stem Cells. Cell Journal (Yakhteh). 2014;16(2):195.

8. Bertani N, Malatesta P, Volpi G, Sonego P, Perris R. Neurogenic potential of human mesenchymal stem cells revisited: analysis by immunostaining, time-lapse video and microarray. Journal of cell science. 2005;118(17):3925-36.

9. Hung SC, Chen NJ, Hsieh SL, Li H, Ma HL, Lo WH. Isolation and Characterization of Size-Sieved Stem Cells from Human Bone Marrow. Stem cells. 2002;20(3):249-58. 
10. Suon S, Jin H, Donaldson AE, Caterson E, Tuan RS, Deschennes G, et al. Transient differentiation of adult human bone marrow cells into neuron-like cells in culture: development of morphological and biochemical traits is mediated by different molecular mechanisms. Stem cells and development. 2004;13(6):625-35.

11. Tao H, Rao R, Ma DD. Cytokine-induced stable neuronal differentiation of human bone marrow mesenchymal stem cells in a serum/feeder cell-free condition. Development, growth \& differentiation. 2005;47(6):423-33.

12. Khoo ML, Shen B, Tao H, Ma DD. Long-term serial passage and neuronal differentiation capability of human bone marrow mesenchymal stem cells. Stem cells and development. 2008;17(5):883-96.

\section{Rosca A-M, Burlacu A. CHARACTERIZATION OF MESENCHYMAL STEM CELLS ISOLATED FROM} MOUSE BONE MARROW. Annals of the Romanian Society for Cell Biology. 2010;15(2).

14. Foudah D, Redondo J, Caldara C, Carini F, Tredici G, Miloso M. Expression of neural markers by undifferentiated rat mesenchymal stem cells. BioMed Research International. 2012;2012.

15. Khoo ML, Tao H, Meedeniya AC, Mackay-Sim A, Ma DD. Transplantation of neuronal-primed human bone marrow mesenchymal stem cells in hemiparkinsonian rodents. PLoS One. 2011;6(5):e19025.

16. Liu Z, Huang D, Zhang M, Chen Z, Jin J, Huang S, et al. Cocaine-and amphetamine-regulated transcript promotes the differentiation of mouse bone marrow-derived mesenchymal stem cells into neural cells. BMC neuroscience. 2011;12(1):67.

17. Jiang Y, Jahagirdar BN, Reinhardt RL, Schwartz RE, Keene CD, Ortiz-Gonzalez XR, et al. Pluripotency of mesenchymal stem cells derived from adult marrow. Nature. 2002;418(6893):41-9. 18. Woodbury D, Schwarz EJ, Prockop DJ, Black IB. Adult rat and human bone marrow stromal cells differentiate into neurons. Journal of neuroscience research. 2000;61(4):364-70. 
19. Sagara J-i, Makino N. Glutathione induces neuronal differentiation in rat bone marrow stromal cells. Neurochemical research. 2008;33(1):16-21.

20. Liu Y, Liu L, Ma X, Yin Y, Tang B, Li Z. Characteristics and neural-like differentiation of mesenchymal stem cells derived from foetal porcine bone marrow. Bioscience reports. 2013;33(2).

21. Sanchez-Ramos J, Song S, Cardozo-Pelaez F, Hazzi C, Stedeford T, Willing A, et al. Adult bone marrow stromal cells differentiate into neural cells in vitro. Experimental neurology. 2000;164(2):247-

56.

22. Bentz K, Molcanyi M, Schneider A, Riess P, Maegele M, Bosche B, et al. Extract derived from rat brains in the acute phase following traumatic brain injury impairs survival of undifferentiated stem cells and induces rapid differentiation of surviving cells. Cellular Physiology and Biochemistry. 2010;26(6):821.

23. Wang X, Wu H, Xue G, Hou Y. Progesterone promotes neuronal differentiation of human umbilical cord mesenchymal stem cells in culture conditions that mimic the brain microenvironment. Neural Regeneration Research. 2012;7(25):1925.

24. Keshteli FZR, Parivar K, Joghatayi MT, Beik HA. Study of the differentiation of rat omentum stem cells to nerve cells using brain tissue extract of Wistar rats. International Journal of Cellular \& Molecular Biotechnology. 2014;2014.

25. Sadan O, Shemesh N, Barzilay R, Dadon-Nahum M, Blumenfeld-Katzir T, Assaf Y, et al. Mesenchymal stem cells induced to secrete neurotrophic factors attenuate quinolinic acid toxicity: a potential therapy for Huntington's disease. Experimental neurology. 2012;234(2):417-27.

26. Brazelton TR, Rossi FM, Keshet GI, Blau HM. From marrow to brain: expression of neuronal phenotypes in adult mice. Science. 2000;290(5497):1775-9. 
27. Cogle CR, Yachnis AT, Laywell ED, Zander DS, Wingard JR, Steindler DA, et al. Bone marrow transdifferentiation in brain after transplantation: a retrospective study. The lancet.

2004;363(9419):1432-7.

28. Coutts M, Keirstead HS. Stem cells for the treatment of spinal cord injury. Experimental neurology. 2008;209(2):368-77. 


\section{Figures}

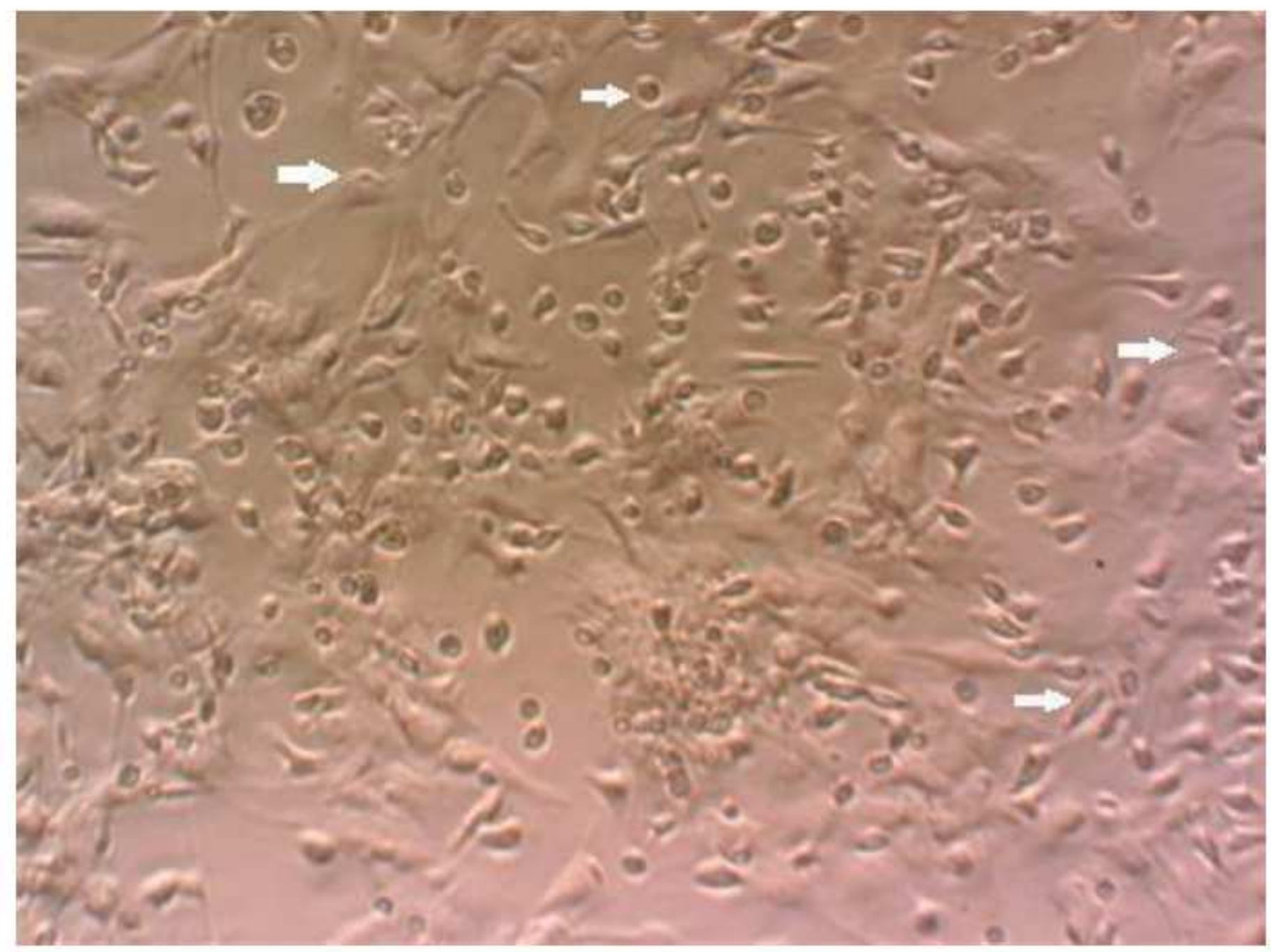

\section{Figure 1}

Cells at P0. Cells with different with morphologies such as round, flattened, or spindle- shaped. 


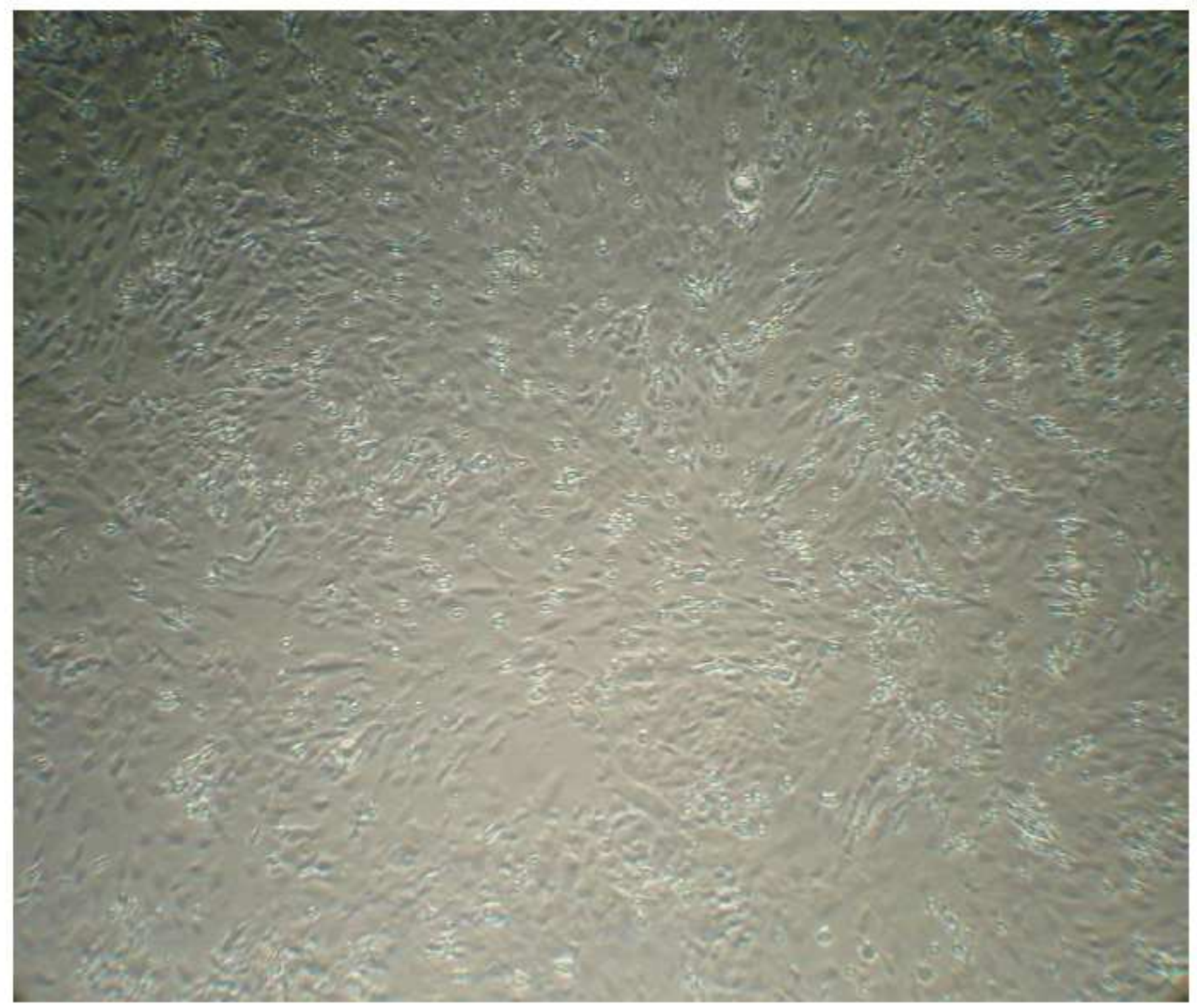

Figure 2

Cells at P3. The majority of cells showed spindle-shaped or fibroblastic morphologies, typical of MSCs. 


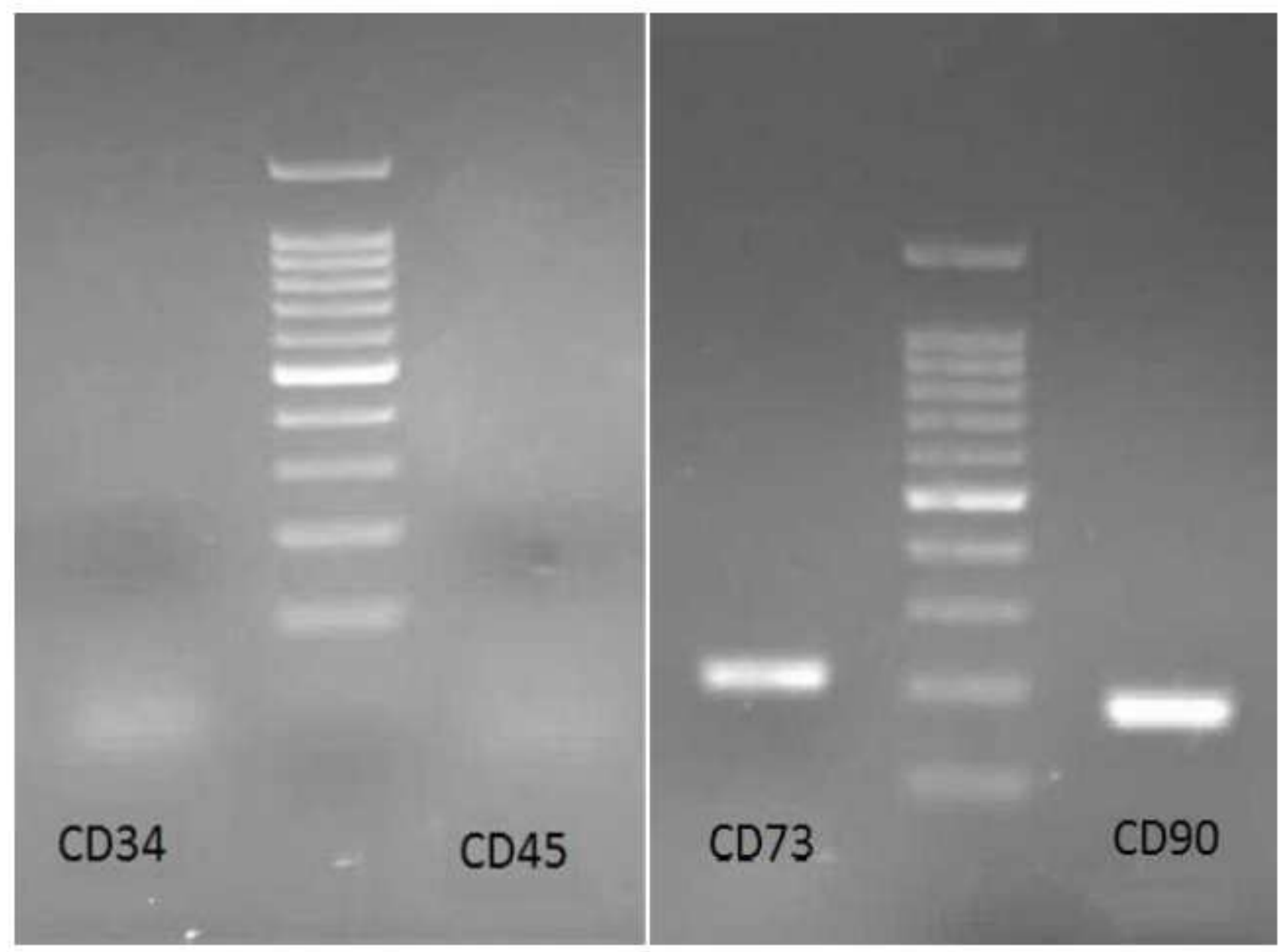

Figure 3

Characterization of MSCs at P3. Left: absence of CD34 (257bp) and CD45 (450bp). Right: presence of CD73 (208bp) and CD90(177bp). Ladders were 100bp. 


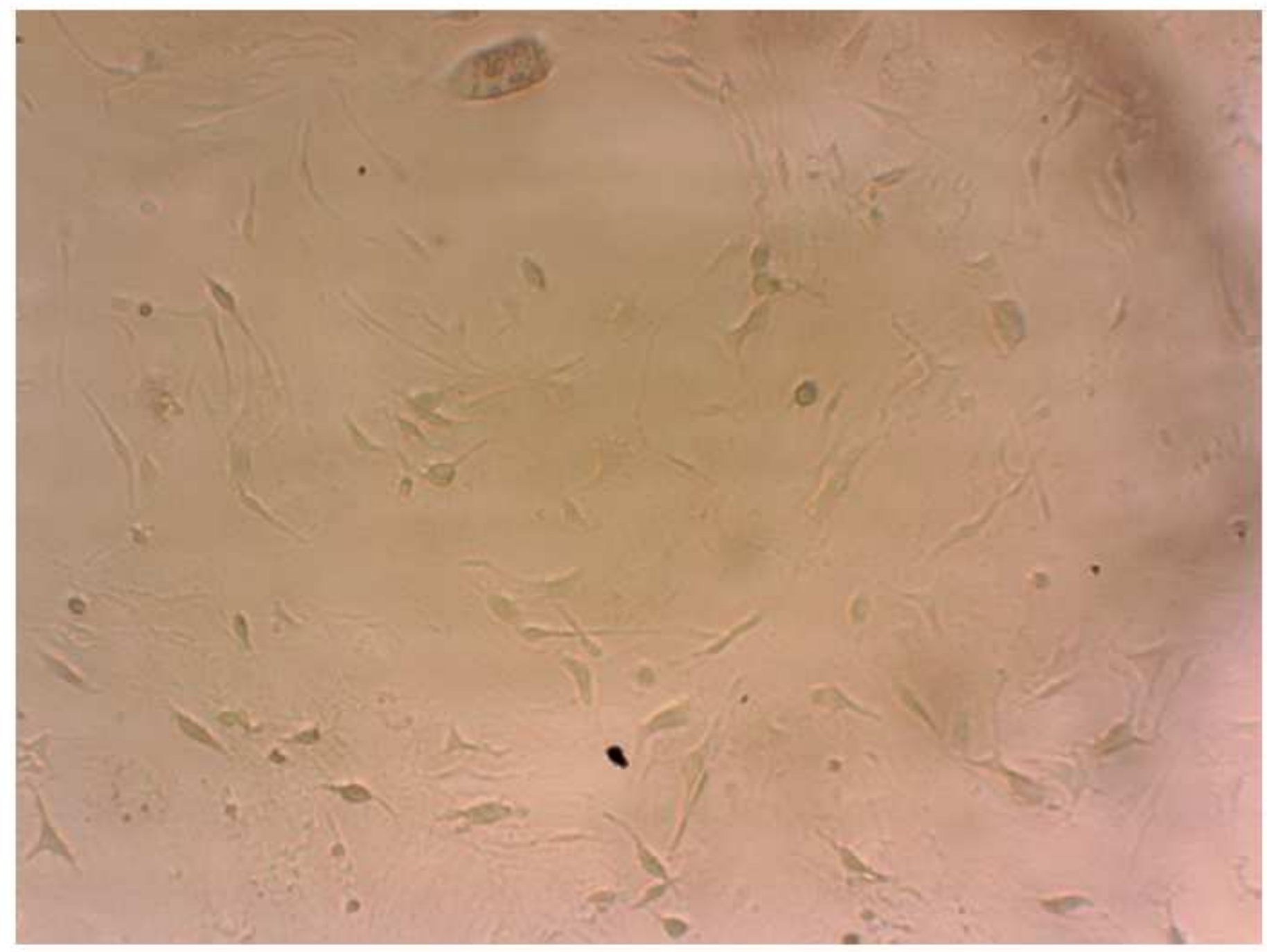

Figure 4

Cells in the group $\mathrm{C}$ on day 3 . Arrows show spindle-shaped morphology. 


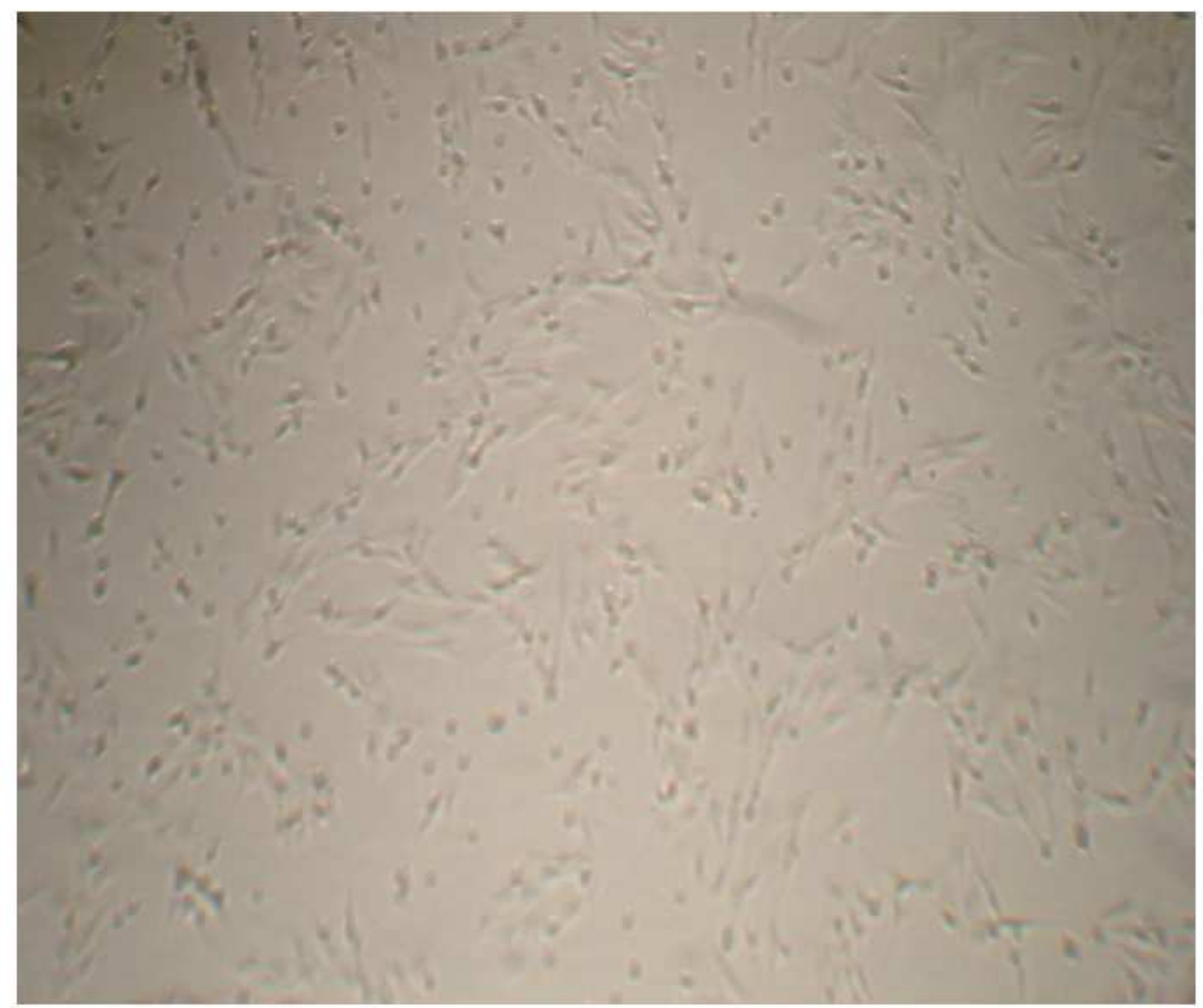

Figure 5

Cells in the group $\mathrm{N}$ on day 3. 


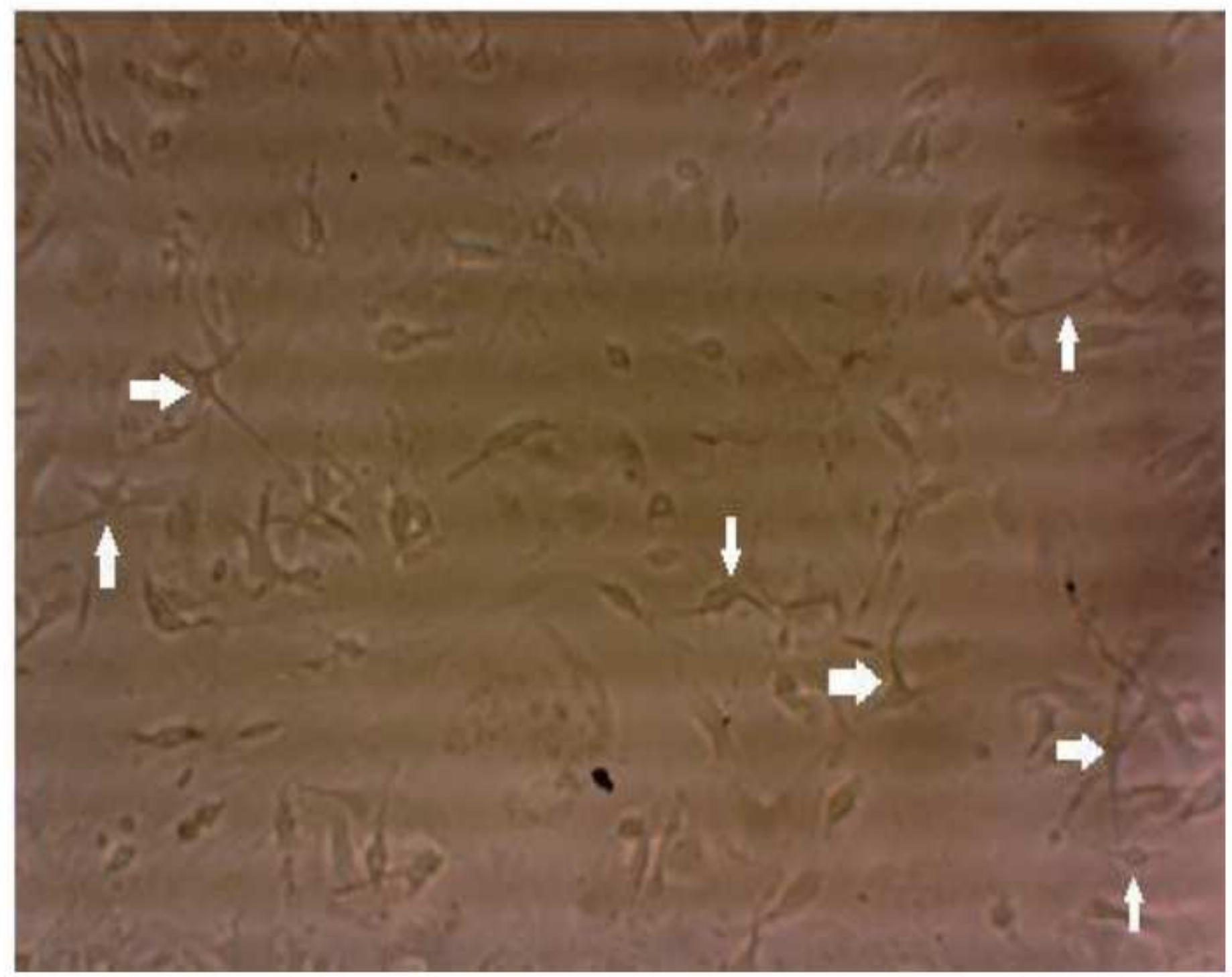

Figure 6

Cells in the group T on day 3. Cells with neural-like morphology were increased. 


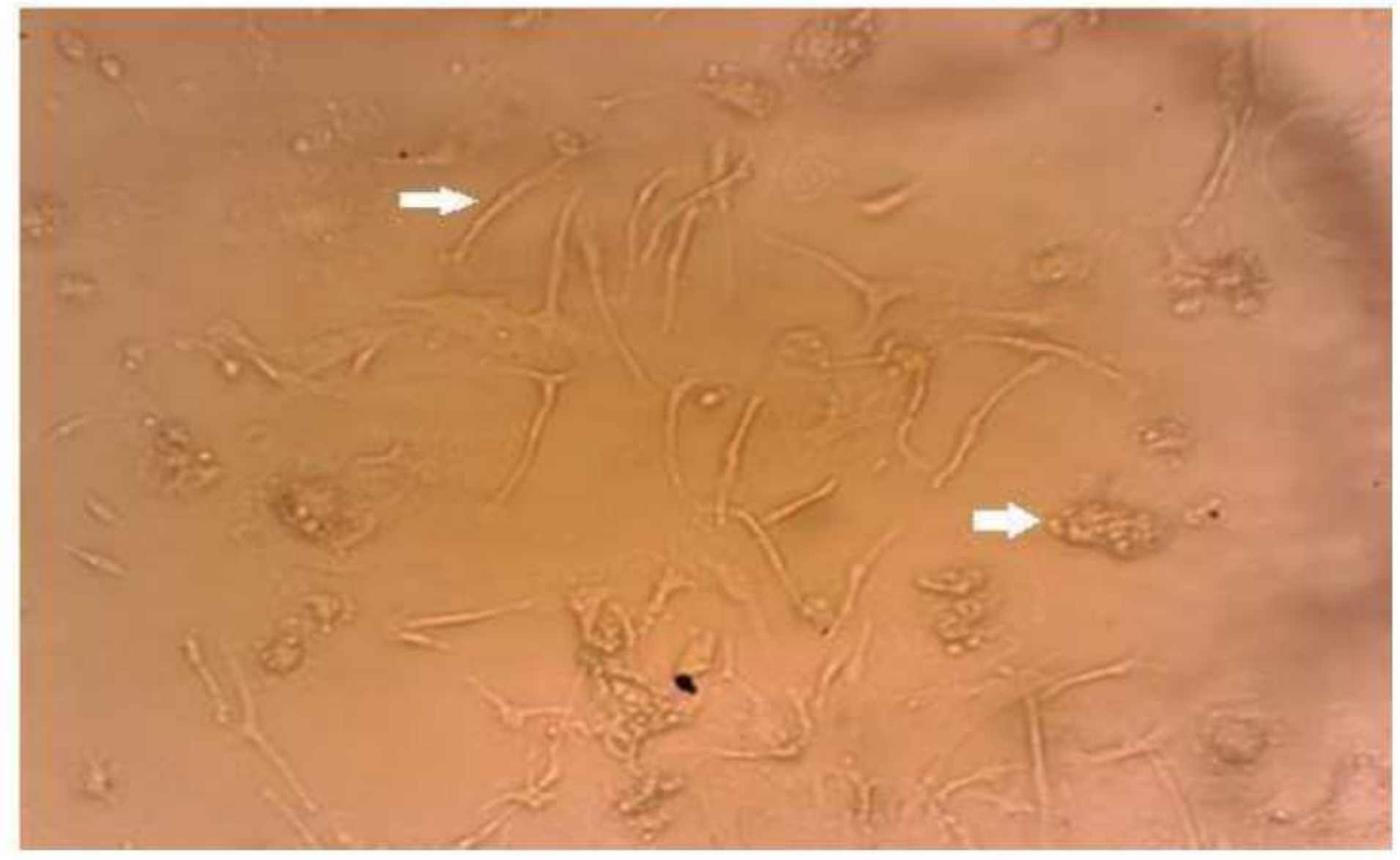

Figure 7

Cells in the group C on day 7. Dead and unhealthy cells were shown. 

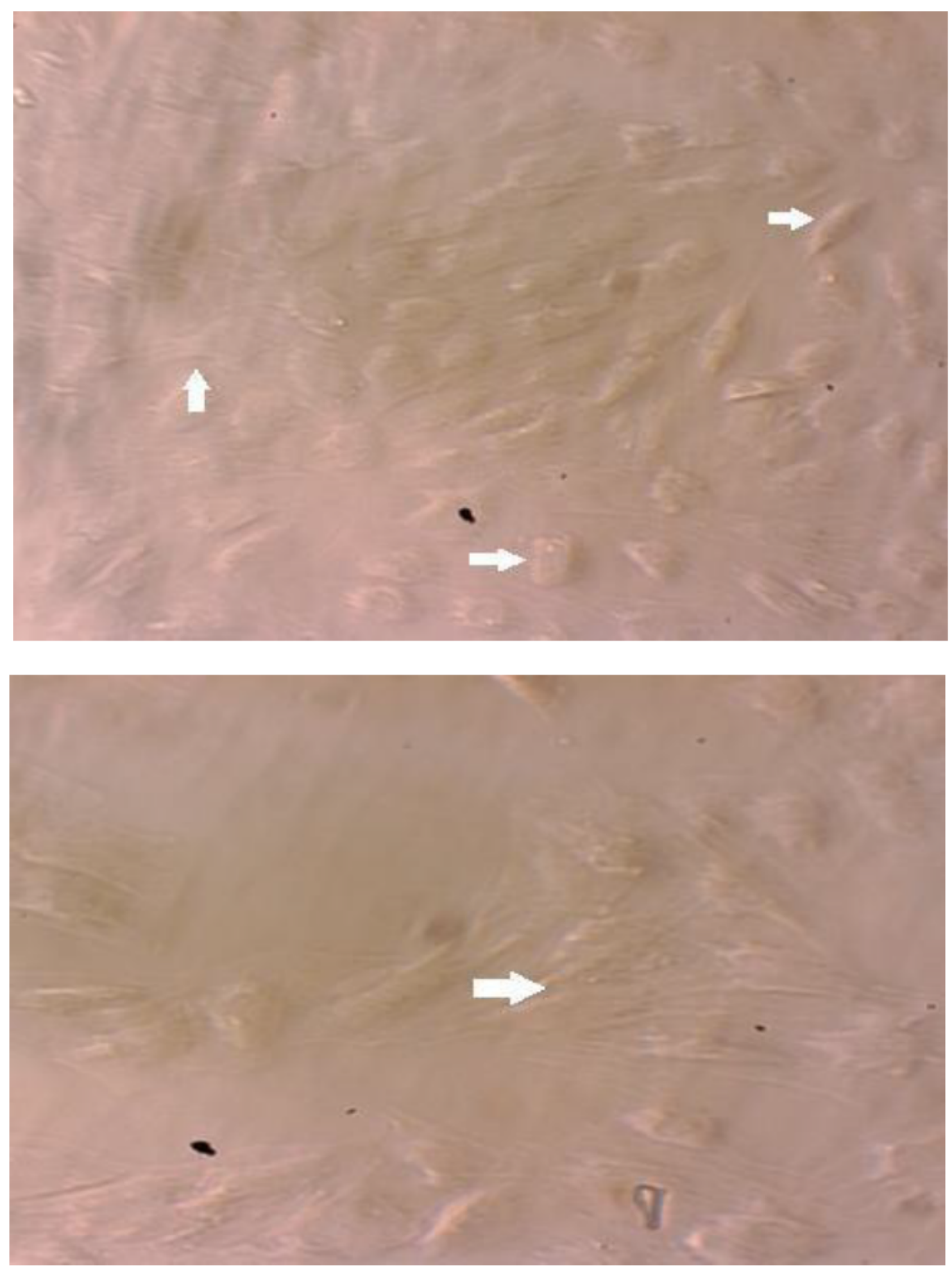

Figure 8

Cells in the group D on day 7. Upper: prevailing of spindle-shaped cells. Down: cells with elongated processes. 

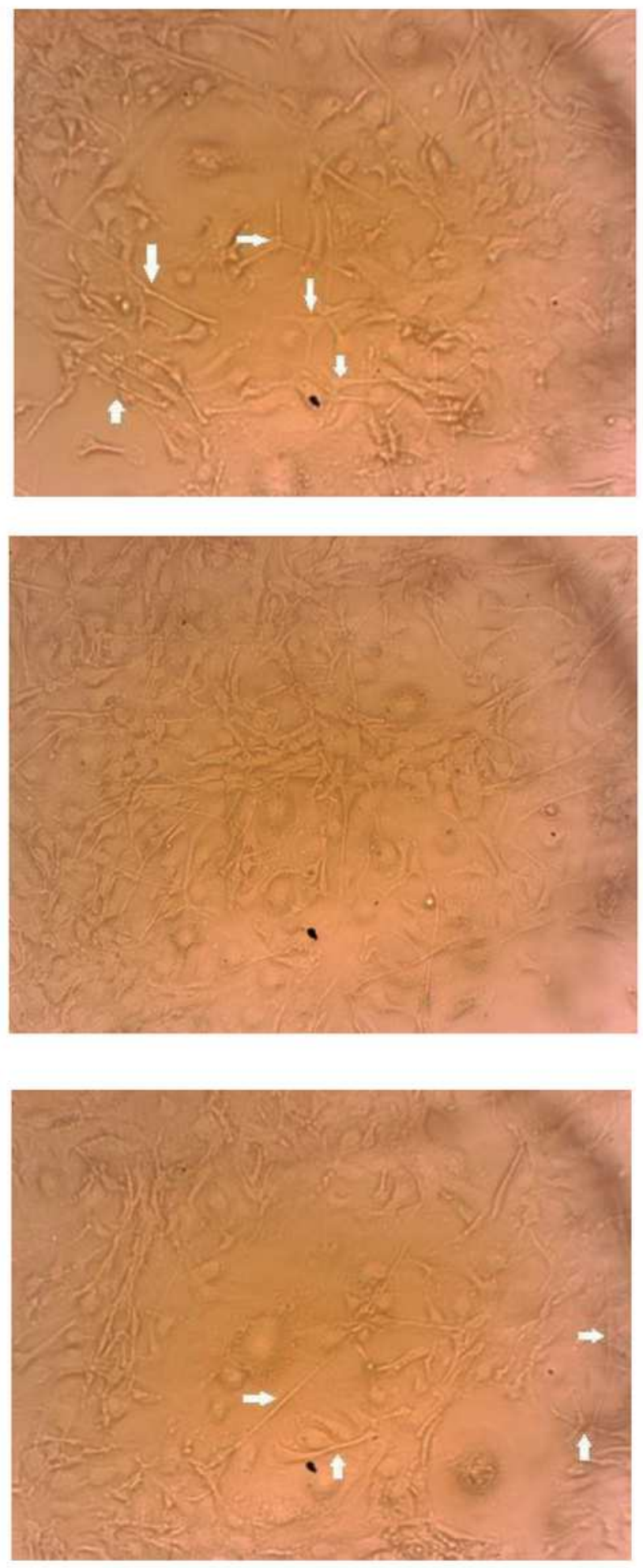

\section{Figure 9}

Cells in the group T on day 7. Upper: neural-like cells with developed processes. Middle: aggregation of cells with neural-like morphology. Down: forming of long branches was considerable in some cells. 


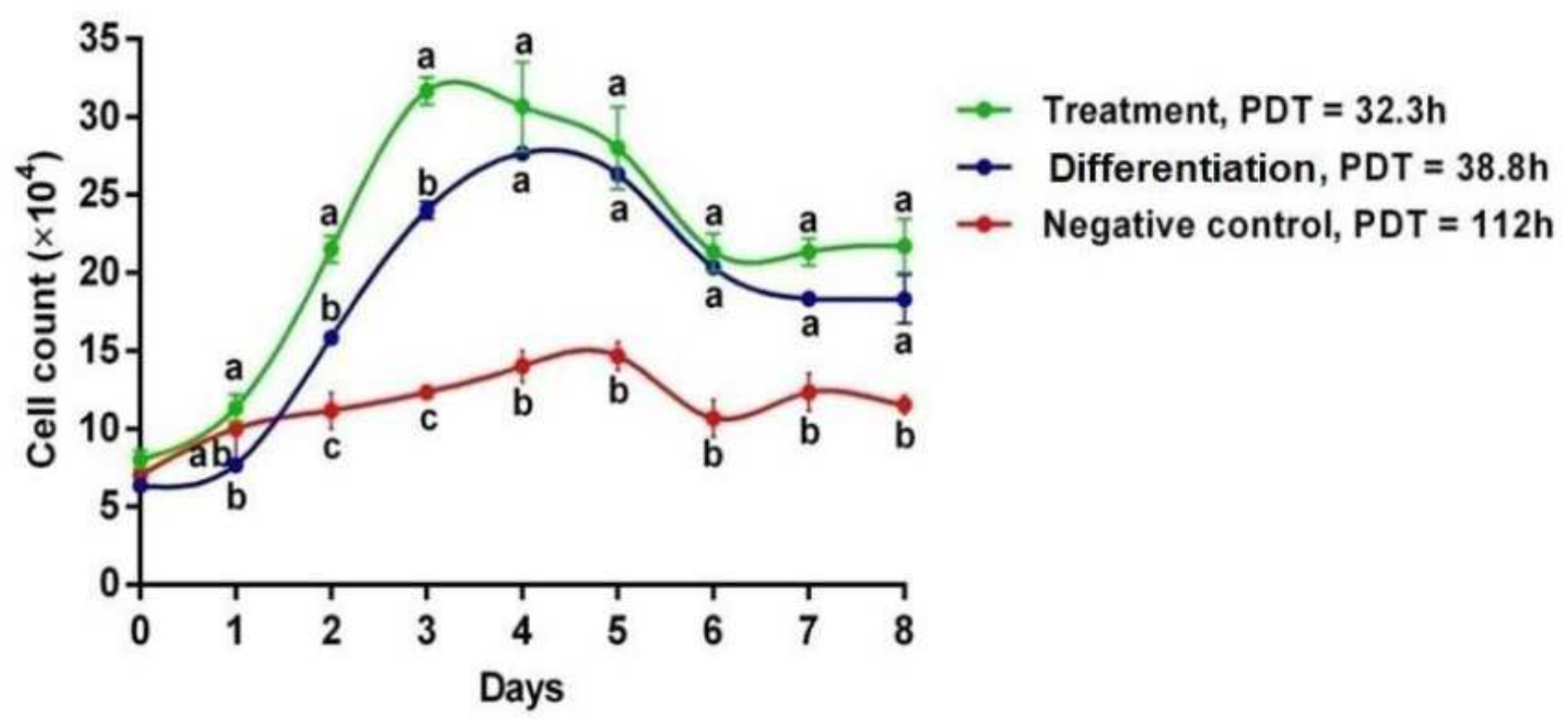

Figure 10

Growth curves of cells throughout the eight days 


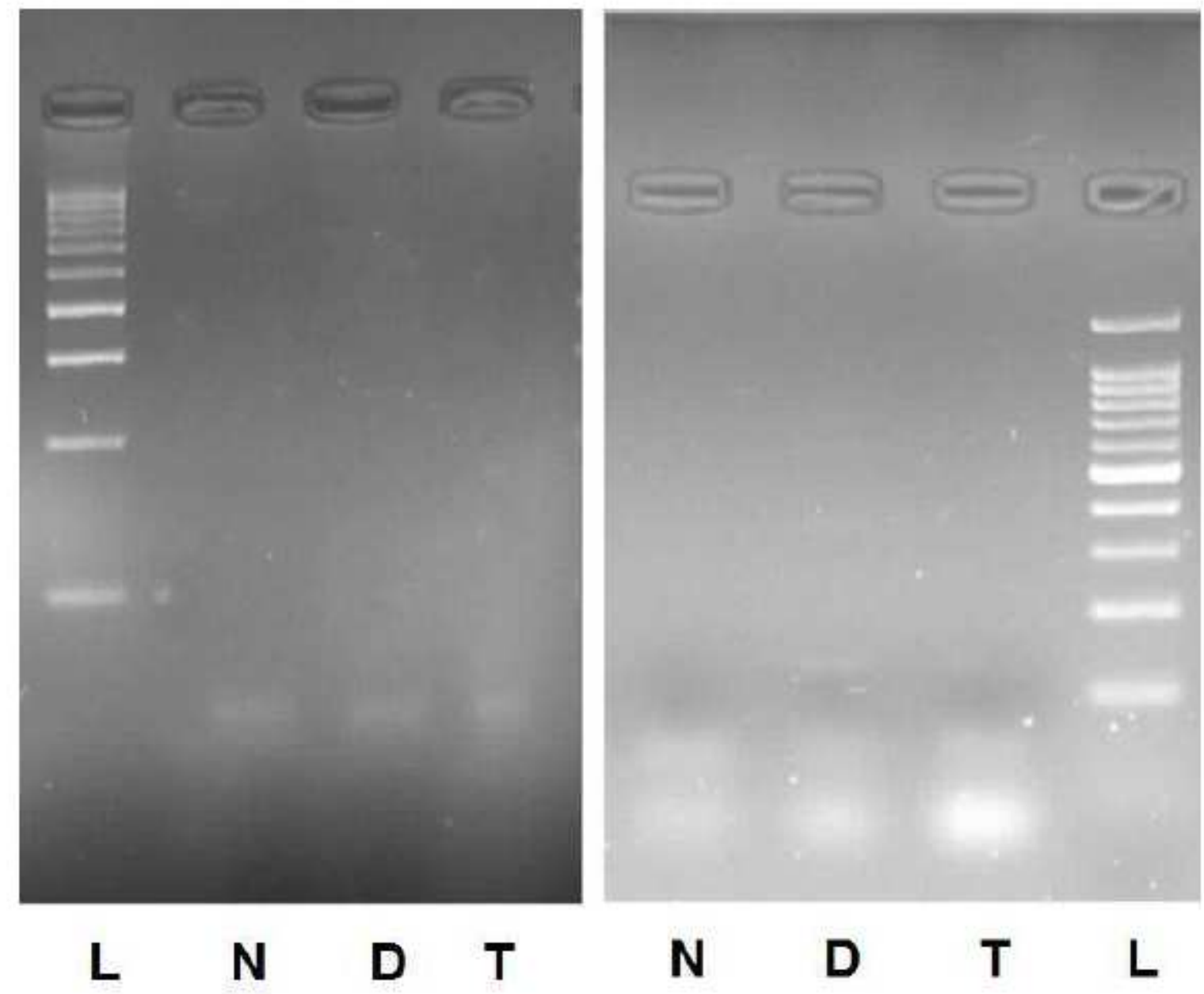

Figure 11

Left and right: GFAP (130 bp) expression pattern on days 3 and 7, respectively. L: 100 bp ladder. N, D, and T stands for negative control, differentiation, and treatment groups. 


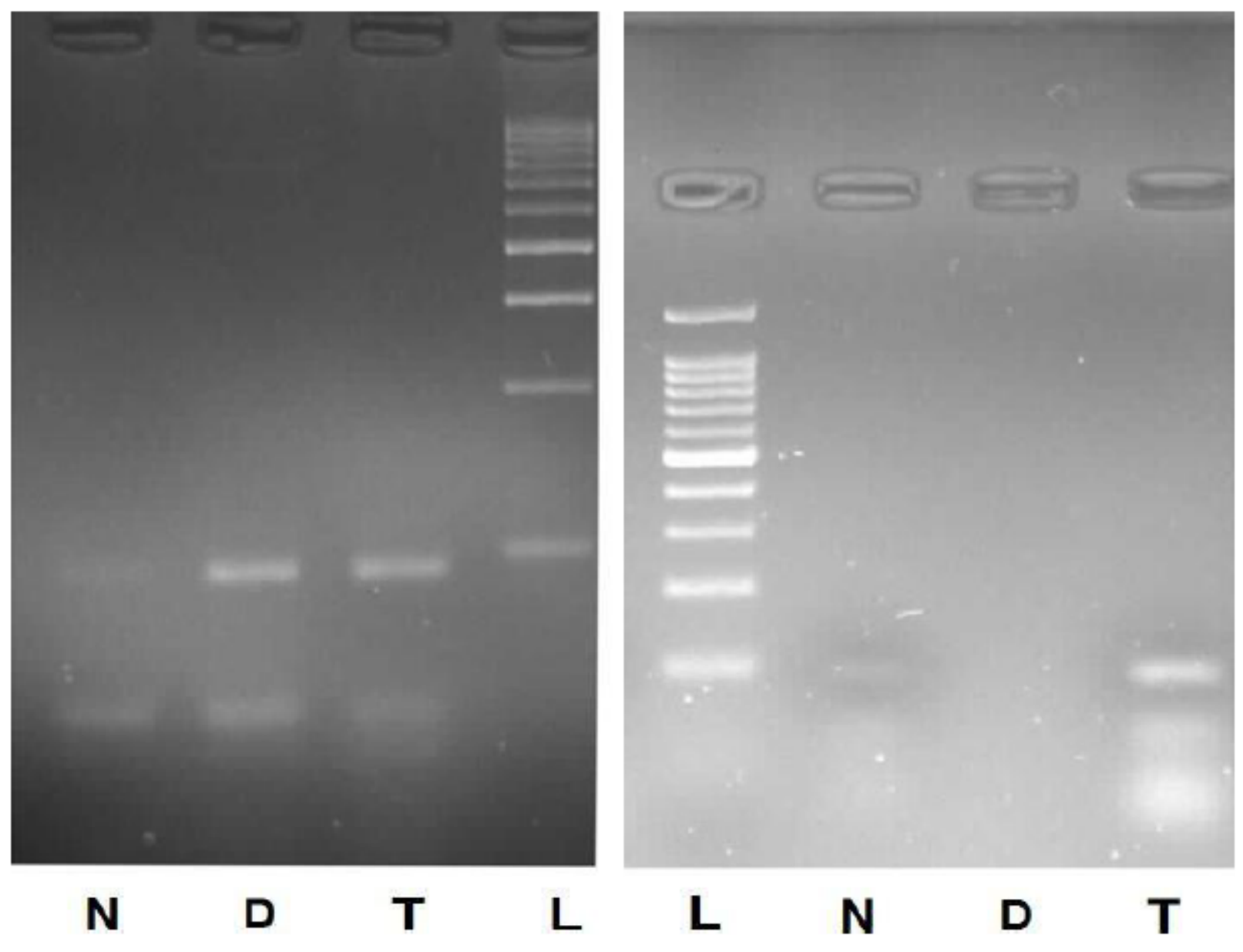

Figure 12

Left and right: GaLC (92 bp) expression pattern on days 3 and 7, respectively. L: 100.bp ladder. N, D, and T stands for negative control, differentiation, and treatment groups 


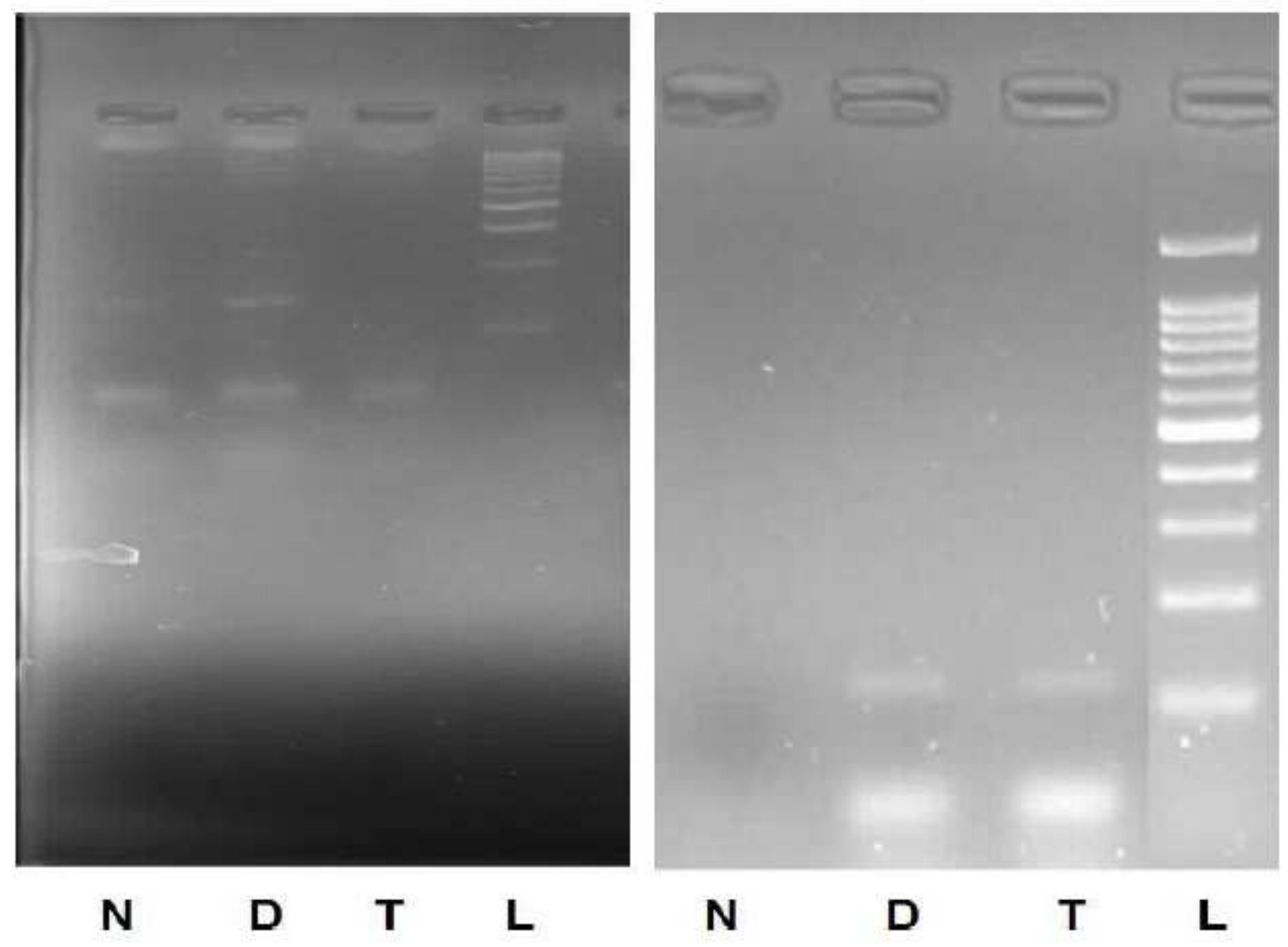

Figure 13

Left and right: ChAT (134 bp) expression patterns on days 3 and 7, respectively. L: 100 bp ladder. N, D, and $T$ stands for negative control, differentiation, and treatment groups. 


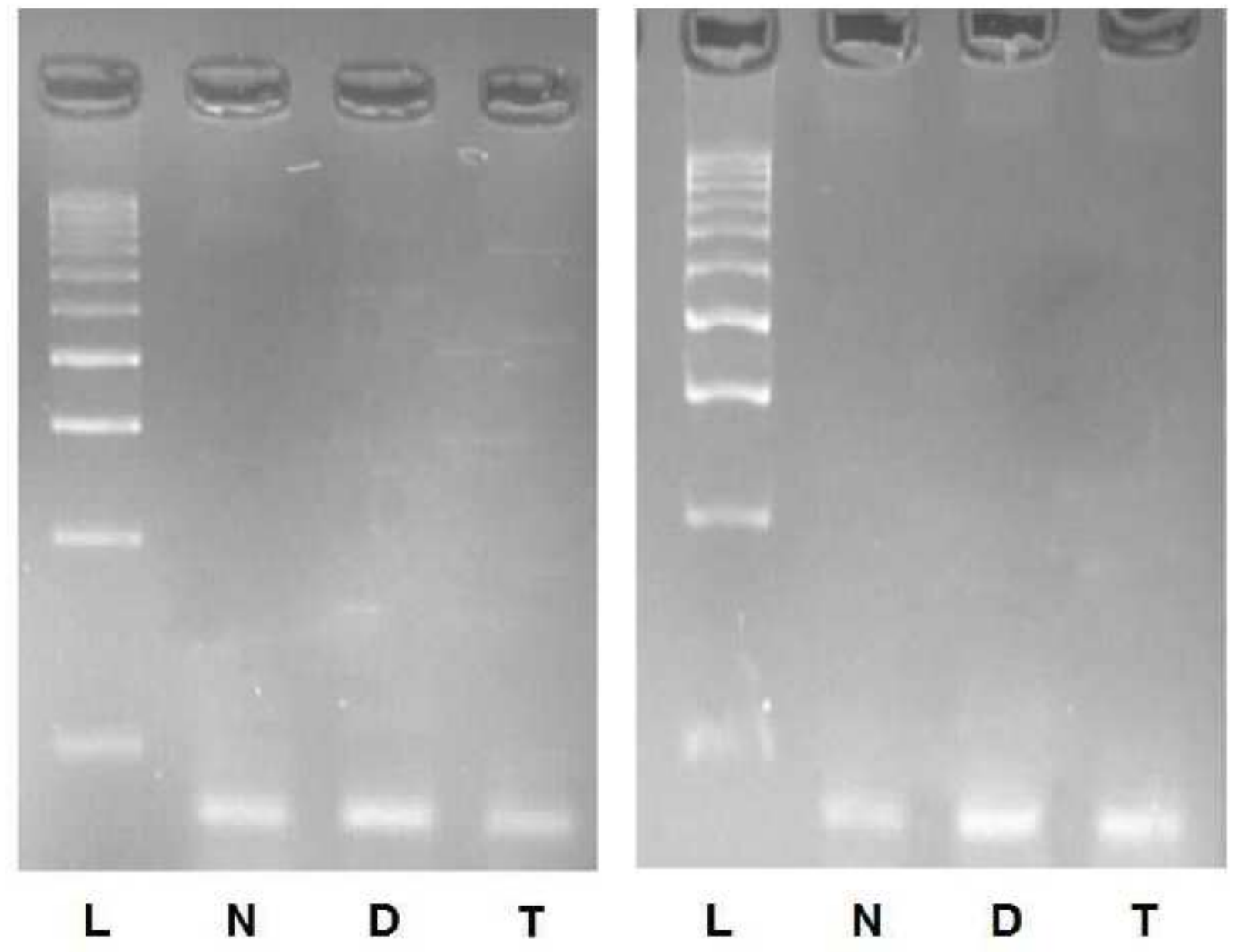

Figure 14

Left and right: TH (81 bp) expression patterns on days three and seven, respectively. L: 100 bp ladder. N, D, and T stands for negative control, differentiation, and treatment groups. 


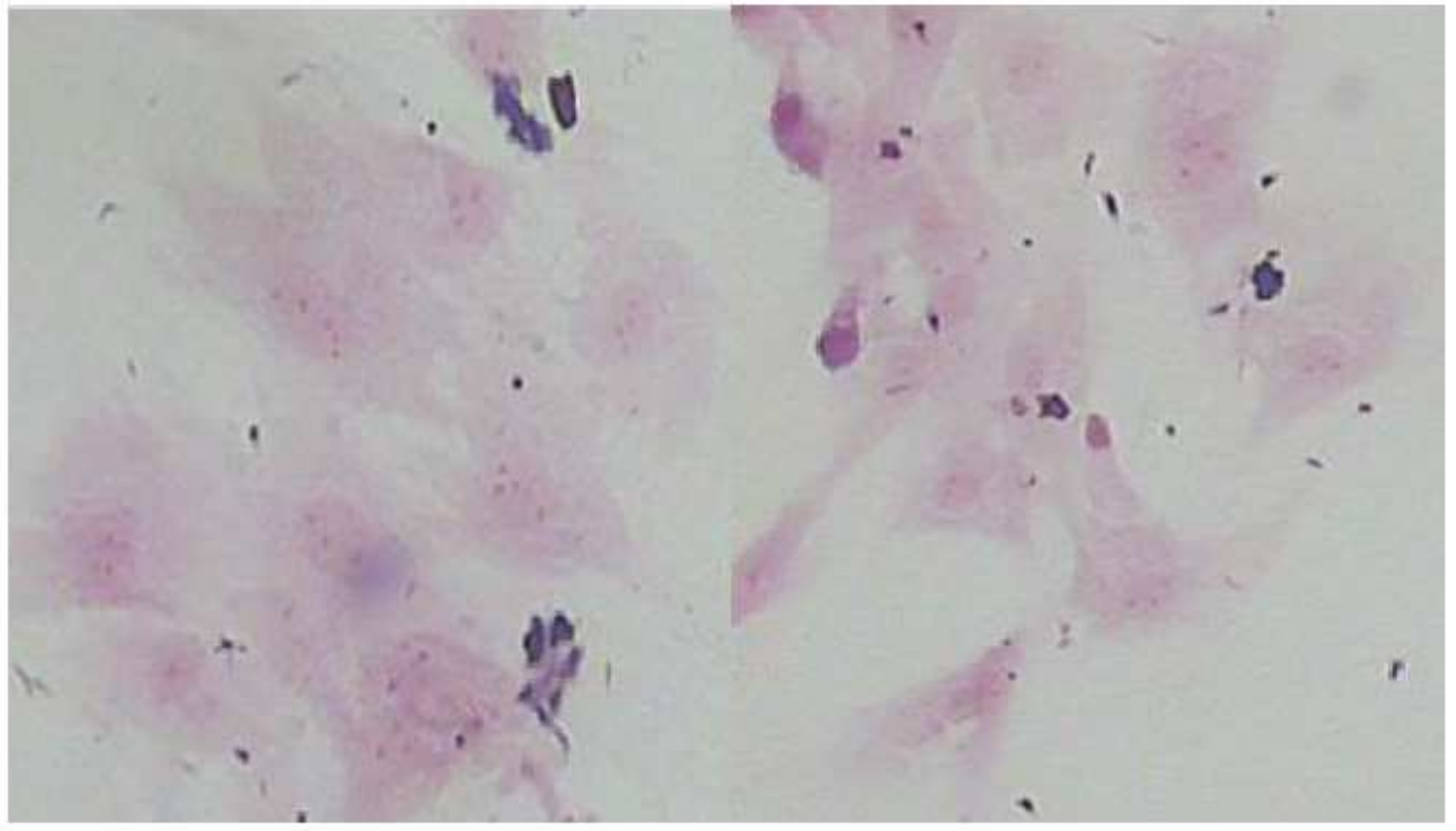

Figure 15

The group $\mathrm{C}$

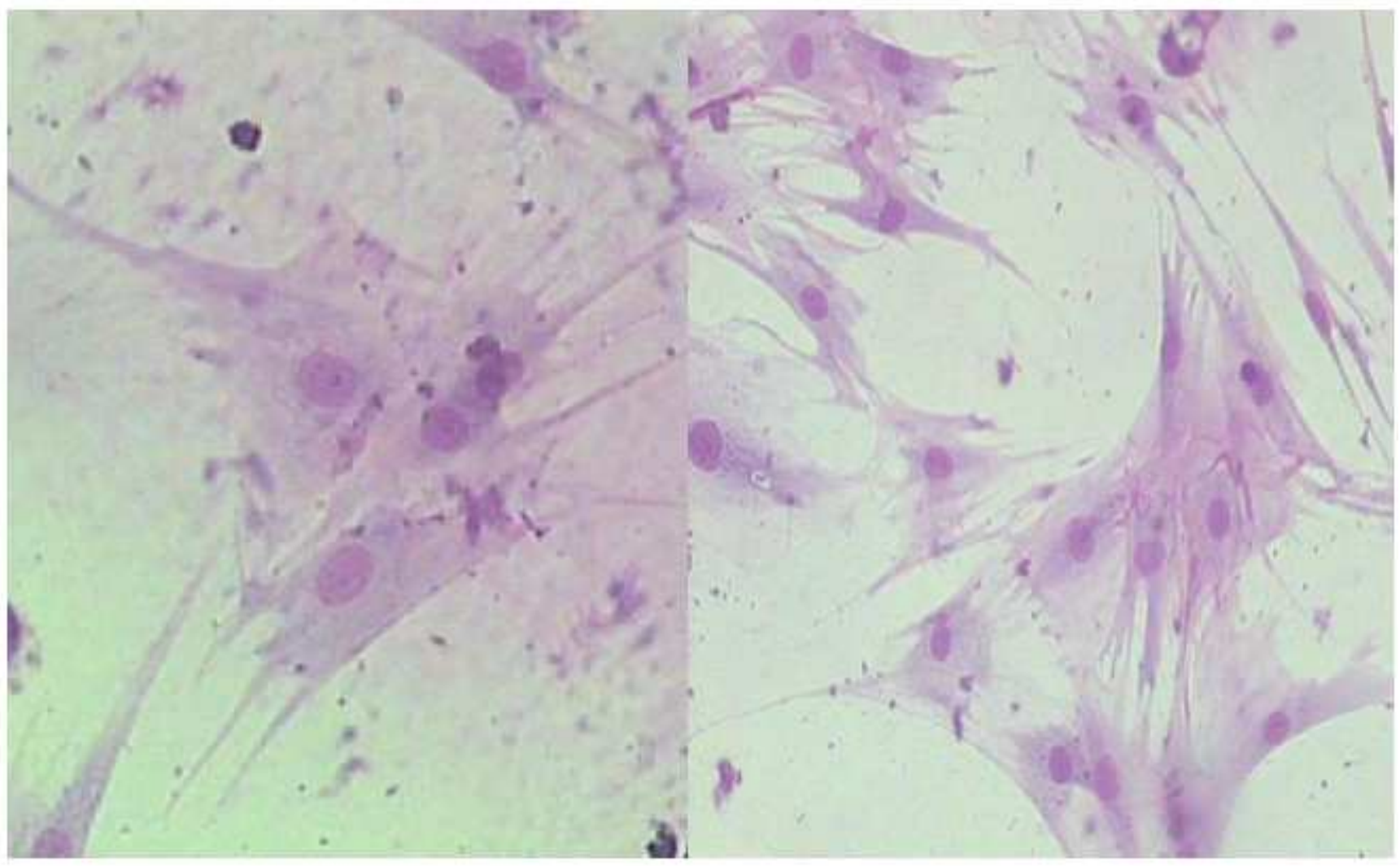


Figure 16

The group $D$

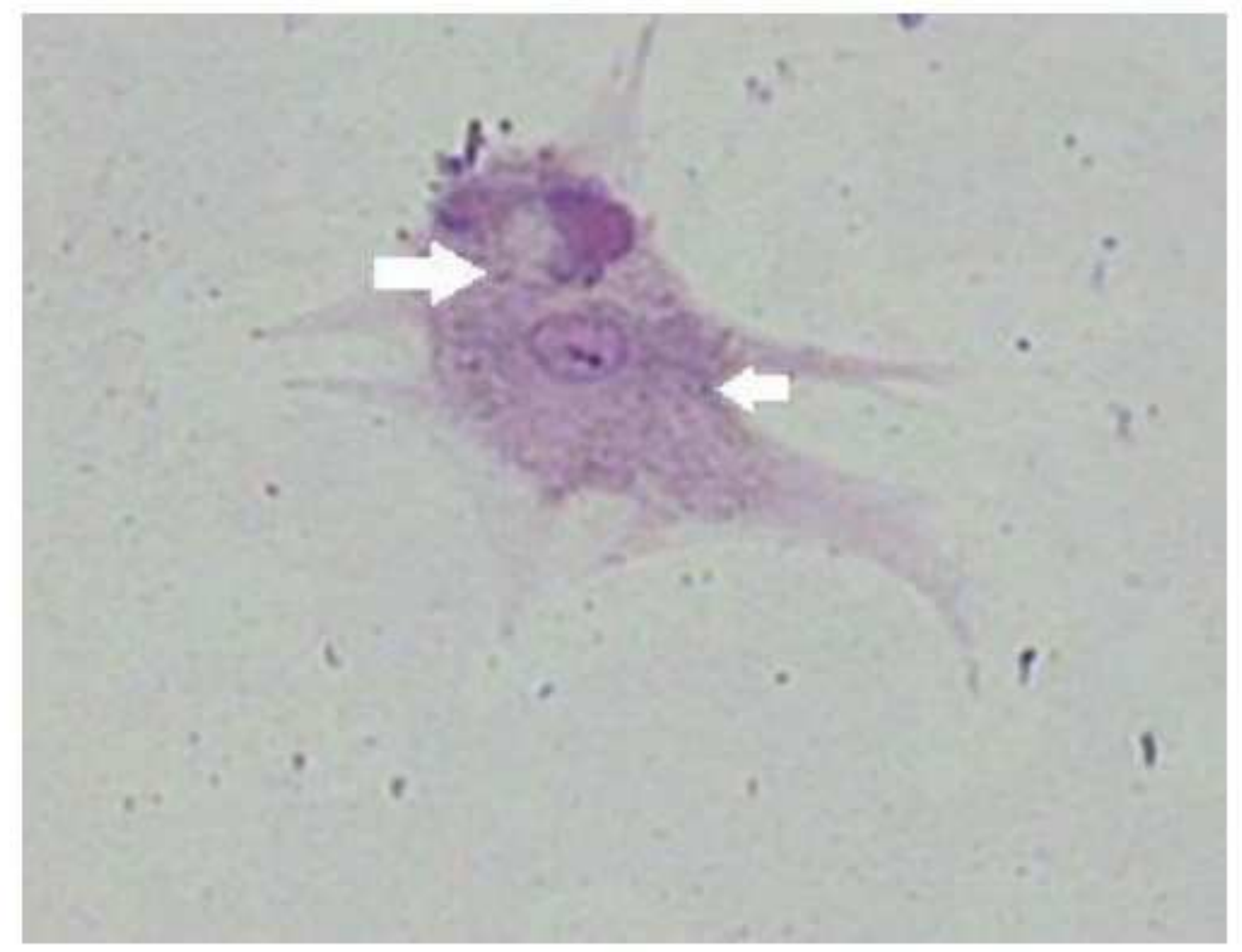

Figure 17

The group T. Arrows point at Nissl bodies. 